\title{
Blast Response of Double Curvature, Composite Sandwich Shallow Shells
}

Michelle S. Hoo Fatt* and Dushyanth Sirivolu

Department of Mechanical Engineering

The University of Akron

Akron, OH 44325-3903

April 5, 2014 (Revised May 19, 2015 and June 25, 2015)

* Professor and Corresponding Author: (330) 972-6308 (phone); (330) 972-6027 (fax); hoofatt@uakron.edu (e-mail) 


\begin{abstract}
An analytical model was developed for predicting the blast response of a double-curvature, composite sandwich shallow shell with PVC foam core. Based on Donnell's nonlinear shallow shell formulation, the PVC foam core was modeled with isotropic and transversely isotropic elastic-plastic properties. The predicted transient response was shown to be in good agreement with Finite Elements (ABAQUS Explicit) when assuming isotropic foam crushing. For sandwich shells with higher curvature and in-plane membrane resistance, lower blast resistance was found with transversely isotropic than isotropic core crushing. This indicated that modeling the core of the sandwich shell as isotropic instead of transversely isotropic would give non-conservative estimates of the structure's ability to resist blast loading for some sandwich shell geometries.
\end{abstract}

Keywords: Composite sandwich shell, core crushing, transverse isotropy, blast response.

\title{
1 Introduction
}

Composite sandwich shells consisting of fiber-reinforced polymer skins and crushable polymeric foam cores are used in naval, aerospace, civil infrastructure and transportation industries. The curved, composite sandwich panels not only provide high specific stiffness and strength but are corrosion-free and low-cost alternatives to their existing metal counterparts. In some cases, these sandwich shells may be exposed to blast or pressure pulse loading. The subsequent response of the sandwich shell can involve transient deformations and vibrations, instability, and/or failure of core and facesheets of the sandwich. Porfiri and Gupta [1] have reviewed some recent work on marine composites subjected to this type of loading. Specialized continuum damage models have been developed by Batra and Hassan [2] to address damage initiation and evolution of fiber-reinforced laminates under blast using finite element analysis. Several multi-layered sandwich shell theories that incorporate higher-order shell kinematics to address transverse core compressibility and shear deformations have been proposed over the last decade to address this problem [3-6]. However, these solutions are restricted to elastic core behavior. In this paper we examine the blast response of composite sandwich shells with crushable foam cores that exhibit elastic-plastic response. 
Recent blast experiments both in the laboratory [7-8] and in the field [9-10], have indicated that an elastic-plastic core is more representative of the blast behaviour of foams used nowadays in composite sandwich construction. While the current design of a sandwich panel under quasi-static loads prohibits plastic crushing of the core, plastic core crushing is inevitable under very high intensity loading, such as one due to a nearby explosion. Plastic core crushing is a desirable feature in blast mitigation. Wang et al. [11] have conducted shock-tube tests on step-wise graded cores with different foam core crushing abilities to show that the blast resistance of a composite sandwich panel can be improved by staggering the foams such that the softest core, which would experience significant core crushing and plasticity, is the first incident layer during transmission of the throughthickness shock wave from a blast. The blast resistance and energy absorption of the composite sandwich panel with step-wise graded cores can be even further enhanced with polyurea interlayers [12].

This paper is concerned with the blast response of a composite sandwich shell with elasticplastic core. Specifically, an analytical model for the transient response and failure of a fullyclamped, double-curvature, composite sandwich panel with a crushable, elastic-plastic polymeric foam core when it is subjected to uniformly-distributed pressure pulse loading is developed. This model follows from previous work by the authors on cylindrical, flat and single curvature sandwich panels [13-15]. Finite element analysis using ABAQUS Explicit is performed to compare model predictions with more refined three-dimensional numerical predictions. This analytical study shall elucidate the effect of core crushing as the sandwich shell undergoes transient deformation under blast loading.

Although many foams are transversely isotropic, they are often assumed to behave in an isotropic manner. In a flat sandwich panel subjected to lateral pressure loading, the foam core resists primarily transverse shear and compression. Modeling the core as an isotropic material with transverse or out-of-plane compression and shear properties is adequate for analysis of flat sandwich panels and often produces accurate solutions. However, in a curved sandwich panel or shell subjected to outer lateral pressure loading, the foam core must resist in-plane compression in addition to transverse shear and compression because of shell curvature. Such in-plane or membrane 
compression may be responsible for local facesheet buckling if the sandwich shell has thin facesheets and a strong core [16]. In Ref. [17], it was shown that both in-plane and out-of-plane compressive normal stresses are about the same magnitude in the elastic core of a composite sandwich shell that is externally loaded by a pressure pulse. Since most structural foams are transversely isotropic $[18,19]$, this indicates that the in-plane foam properties would be needed to accurately determine the response of a composite sandwich shell, which carries much of the lateral blast load in membrane compression. Solutions for the blast response of a composite sandwich shell with isotropic core crushing as well as a transversely isotropic core crushing are given and compared in this paper.

\section{Problem Formulation}

The double-curvature, composite sandwich shell is defined in Fig. 1 with facesheet thickness $h$ and core thickness $\mathrm{H}$. The mid-surfaces of the composite facesheets are defined with radius $\mathrm{R}_{\mathrm{x}_{1}}, \mathrm{R}_{\mathrm{y}_{1}}, \mathrm{R}_{\mathrm{x}_{2}}$ and $\mathrm{R}_{\mathrm{y}_{2}}$. Curvilinear coordinates $\mathrm{x}_{1}, \mathrm{y}_{1}, \mathrm{z}_{1}$ and $\mathrm{x}_{2}, \mathrm{y}_{2}, \mathrm{z}_{2}$ are defined with respect to the outer and inner facesheets, respectively. The sandwich shell is fully clamped along all edges, and is considered to be shallow; i.e., a shell with a rise-to-span ratio of less than approximately 1/5 [20-22]. This sandwich shell is subjected to uniformly-distributed pressure pulse of amplitude $\mathrm{p}_{\mathrm{o}}$ and duration $\Delta \mathrm{T}$, which is given by

$\mathrm{p}(\mathrm{t})=\left\{\begin{array}{l}\mathrm{p}_{0}\left(1-\frac{\mathrm{t}}{\Delta \mathrm{T}}\right), 0 \leq \mathrm{t} \leq \Delta \mathrm{T} \\ 0, \text { otherwise }\end{array}\right.$

The above triangular pulse load is a simplification of the blast loading on a structure. In an actual explosion, charge weight, stand-off distance and reflected pressure waves affect the actual pressure distribution on the surface of the structure. An exponentially-decaying pressure time history is usually what is measured in blast experiments, but triangular pulse load is a good approximation of the initial stages of this loading history. It should be noted that this paper does not model an actual explosion, but rather gives a solution methodology that one can use to model blast response of a sandwich shell with an elastic-plastic core. 
The composite sandwich shells considered in this paper are composed of fiber-reinforced polymeric facesheets and PVC foam cores. The mass density of facesheets and core are $\rho_{\mathrm{f}}$ and $\rho_{\mathrm{c}}$, respectively. The facesheets are considered to be orthotropic, linear elastic-brittle material, while the core is idealized as an elastic, perfectly-plastic material. As in our previous work [13-15, 17], the following assumptions concerning sandwich material behaviors are made:

1. Foam cores do not experience appreciable crushing (core compression) before facesheet fracture so that they can be described as an elastic, perfectly-plastic material. This assumption is generally applicable to uniformly-loaded composite sandwich panels with fiber-reinforced polymeric facesheets that are brittle (fracture strains less than 5\% [23]) because the facesheet would fracture long before core densification. It may not be true for more localized loading, however.

2. There is perfect bonding between facesheet and core. The validity of this assumption depends on adhesion between facesheet and core. In many cases a good choice of adhesive and bonding practice ensures that there is perfect adhesion between core and facesheets. Gdoutos and Daniel [24] have examined failure modes of composite sandwich beam that were perfectly bonded and subjected to four-point bend tests. They have documented core failure due to transverse shear cracking along lines approximately 45 degrees to a transverse crosssectional plane; this was followed by cracking just under and parallel to the bond line between facesheet and core [24]. Post-mortem sectioning of fully clamped composite sandwich panels subjected to air-blast in Ref. [10] also indicates similar shear cracking patterns in the core.

3. Strain rate effects in both facesheet and core material behaviour are neglected. Under blast loading, facesheet and core materials experience high strain rates. Fiber-reinforced polymer and polymer foam materials are best described by dynamic constitutive relations since experiments indicate that they exhibit rate-dependent behaviors $[25,26]$. 


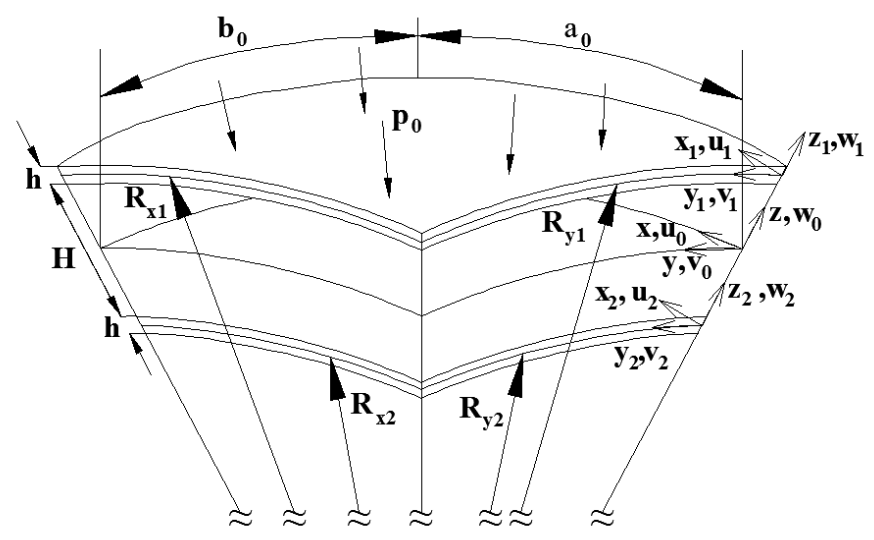

Figure 1 Geometry and loading of double curvature sandwich shell.

\subsection{Facesheet kinematics}

Donnell's nonlinear shallow shell theory is used to obtain the strain-displacement relations in the outer facesheet $(i=1)$ and inner facesheet $(i=2)$ :

$$
\begin{aligned}
& \varepsilon_{\mathrm{x}_{\mathrm{i}}}=\varepsilon_{\mathrm{x}_{\mathrm{i}}, \mathrm{m}}+\mathrm{z}_{\mathrm{i}} \kappa_{\mathrm{x}_{\mathrm{i}}} \\
& \varepsilon_{\mathrm{y}_{\mathrm{i}}}=\varepsilon_{\mathrm{y}_{\mathrm{i}}, \mathrm{m}}+\mathrm{z}_{\mathrm{i}} \kappa_{\mathrm{y}_{\mathrm{i}}} \\
& \gamma_{\mathrm{x}_{\mathrm{i}} \mathrm{y}_{\mathrm{i}}}=\gamma_{\mathrm{x}_{\mathrm{i}} \mathrm{y}_{\mathrm{i}}, \mathrm{m}}+\mathrm{z}_{\mathrm{i}} \kappa_{\mathrm{x}_{\mathrm{i}} \mathrm{y}_{\mathrm{i}}}
\end{aligned}
$$

where the mid-surface strain and the change in curvature in the outer and inner facesheets are

$$
\begin{aligned}
& \varepsilon_{\mathrm{x}_{\mathrm{i}}, \mathrm{m}}=\frac{\partial \mathrm{u}_{\mathrm{i}}}{\partial \mathrm{x}_{\mathrm{i}}}+\frac{\mathrm{w}_{\mathrm{i}}}{\mathrm{R}_{\mathrm{x}_{\mathrm{i}}}}+\frac{1}{2}\left(\frac{\partial \mathrm{w}_{\mathrm{i}}}{\partial \mathrm{x}_{\mathrm{i}}}\right)^{2} \\
& \varepsilon_{\mathrm{y}_{\mathrm{i}}, \mathrm{m}}=\frac{\partial \mathrm{v}_{\mathrm{i}}}{\partial \mathrm{y}_{\mathrm{i}}}+\frac{\mathrm{w}_{\mathrm{i}}}{\mathrm{R}_{\mathrm{y}_{\mathrm{i}}}}+\frac{1}{2}\left(\frac{\partial \mathrm{w}_{\mathrm{i}}}{\partial \mathrm{y}_{\mathrm{i}}}\right)^{2} \\
& \gamma_{\mathrm{x}_{\mathrm{i}} \mathrm{y}_{\mathrm{i}}, \mathrm{m}}=\frac{\partial \mathrm{u}_{\mathrm{i}}}{\partial \mathrm{y}_{\mathrm{i}}}+\frac{\partial \mathrm{v}_{\mathrm{i}}}{\partial \mathrm{x}_{\mathrm{i}}}+\frac{\partial \mathrm{w}_{\mathrm{i}}}{\partial \mathrm{x}_{\mathrm{i}}} \frac{\partial \mathrm{w}_{\mathrm{i}}}{\partial \mathrm{y}_{\mathrm{i}}} \\
& \kappa_{\mathrm{x}_{\mathrm{i}}}=-\frac{\partial^{2} \mathrm{w}_{\mathrm{i}}}{\partial \mathrm{x}_{\mathrm{i}}^{2}} \\
& \kappa_{\mathrm{y}_{\mathrm{i}}}=-\frac{\partial^{2} \mathrm{w}_{\mathrm{i}}}{\partial \mathrm{y}_{\mathrm{i}}^{2}}
\end{aligned}
$$


$\kappa_{\mathrm{x}_{\mathrm{i}} \mathrm{y}_{\mathrm{i}}}=-2 \frac{\partial^{2} \mathrm{w}_{\mathrm{i}}}{\partial \mathrm{x}_{\mathrm{i}} \partial \mathrm{y}_{\mathrm{i}}}$

This non-linear shell theory was chosen to describe facesheet strain-displacement relations because of its simplicity and accuracy for shallow shell [27].

\subsection{Core kinematics}

As indicated in Figure 1, the core mid-surface is located at mean radii:

$$
\begin{aligned}
& \mathrm{R}_{\mathrm{x}}=\frac{1}{2}\left(\mathrm{R}_{\mathrm{x}_{1}}+\mathrm{R}_{\mathrm{x}_{2}}\right) \\
& \mathrm{R}_{\mathrm{y}}=\frac{1}{2}\left(\mathrm{R}_{\mathrm{y}_{1}}+\mathrm{R}_{\mathrm{y}_{2}}\right)
\end{aligned}
$$

and it is defined with a set of curvilinear coordinates $\mathrm{x}, \mathrm{y}, \mathrm{z}$. Core deformations, $\mathrm{w}_{\mathrm{o}}, \mathrm{u}_{0}$ and $\mathrm{v}_{\mathrm{o}}$, are assumed to be compatible with the facesheet deflections so that

$$
\begin{aligned}
& \mathrm{w}_{0}=\frac{\mathrm{w}_{1}+\mathrm{w}_{2}}{2} \\
& \mathrm{u}_{0}=\frac{\mathrm{u}_{1}+\mathrm{u}_{2}}{2} \\
& \mathrm{v}_{0}=\frac{\mathrm{v}_{1}+\mathrm{v}_{2}}{2}
\end{aligned}
$$

The in-plane strain-displacement relations for the core are

$$
\begin{aligned}
& \varepsilon_{\mathrm{x}}=\varepsilon_{\mathrm{x}, \mathrm{m}}+\mathrm{z} \kappa_{\mathrm{x}} \\
& \varepsilon_{\mathrm{y}}=\varepsilon_{\mathrm{y}, \mathrm{m}}+\mathrm{z} \kappa_{\mathrm{y}} \\
& \gamma_{\mathrm{xy}}=\gamma_{\mathrm{xy}, \mathrm{m}}+\mathrm{z} \kappa_{\mathrm{xy}}
\end{aligned}
$$

where the mid-surface strain and the change in curvature are

$$
\begin{aligned}
& \varepsilon_{x, m}=\frac{\partial u_{0}}{\partial x}+\frac{w_{0}}{R_{x}}+\frac{1}{2}\left(\frac{\partial w_{0}}{\partial x}\right)^{2} \\
& \varepsilon_{y, m}=\frac{\partial v_{0}}{\partial y}+\frac{w_{0}}{R_{y}}+\frac{1}{2}\left(\frac{\partial w_{0}}{\partial y}\right)^{2} \\
& \gamma_{x y, m}=\frac{\partial u_{0}}{\partial y}+\frac{\partial v_{0}}{\partial x}+\frac{\partial w_{0}}{\partial x} \frac{\partial w_{0}}{\partial y}
\end{aligned}
$$




$$
\kappa_{x}=\frac{\partial \phi_{y}}{\partial x}
$$

$\kappa_{y}=\frac{\partial \phi_{x}}{\partial y}$

$\kappa_{x y}=\frac{\partial \phi_{y}}{\partial y}+\frac{\partial \phi_{x}}{\partial x}+\frac{1}{2}\left(\frac{1}{R_{y}}-\frac{1}{R_{x}}\right)\left(\frac{\partial v_{0}}{\partial x}-\frac{\partial u_{0}}{\partial y}\right)$

and $\phi_{y}$ and $\phi_{x}$ are rotations of plane sections about the $\mathrm{x}$ - and y-axes, respectively. The nonlinear terms may be neglected for thick cores if the sandwich shell deflections are small compared to the full thickness of sandwich shell. Transverse shear strains in the core are given by

$$
\begin{aligned}
& \gamma_{\mathrm{xz}}=\phi_{\mathrm{y}}+\frac{\partial \mathrm{w}_{0}}{\partial \mathrm{x}}-\frac{\mathrm{u}_{0}}{\mathrm{R}_{\mathrm{x}}} \\
& \gamma_{\mathrm{yz}}=\phi_{\mathrm{x}}+\frac{\partial \mathrm{w}_{0}}{\partial \mathrm{y}}-\frac{\mathrm{v}_{0}}{\mathrm{R}_{\mathrm{y}}}
\end{aligned}
$$

The following approximations are made for the rotations of plane sections and the radial compressive strains:

$$
\begin{aligned}
& \phi_{\mathrm{y}}=\frac{\mathrm{u}_{1}-\mathrm{u}_{2}}{\mathrm{H}} \\
& \phi_{\mathrm{x}}=\frac{\mathrm{v}_{1}-\mathrm{v}_{2}}{\mathrm{H}} \\
& \varepsilon_{\mathrm{z}}=\frac{\mathrm{w}_{1}-\mathrm{w}_{2}}{\mathrm{H}}
\end{aligned}
$$

Equations (27)-(29) are first-order approximations for rotations and compressive strains in the core. The first two assumptions regarding rotations of plane sections ignore deformation due to bending strains in the facesheets and suggest that plane cross-sections of the core rotate with a constant angle. The last assumption is equivalent to assuming a linear variation in radial deformations of the core. As a result of these assumptions, transverse shear and normal strains within the core are assumed to be uniformly-distributed through the thickness, i.e. they do not depend on z-coordinate. While there are more accurate, higher-order theories to describe core deformations [5-6], they were not chosen 
because of the resulting complexities that would have resulted in the setting up the following equations of motion.

\subsection{Transient response of shell}

Out-of-plane and in-plane deflections of the facesheets are expressed in double Fourier series as follows:

$$
\begin{aligned}
& \mathrm{w}_{1}=\sum_{\mathrm{n}=0}^{\infty} \sum_{\mathrm{m}=0}^{\infty} \mathrm{a}_{\mathrm{mn}}\left(1-\cos \frac{2 \pi \mathrm{x}_{1}}{\mathrm{a}_{0}}\right)\left(1-\cos \frac{2 \pi \mathrm{y}_{1}}{\mathrm{~b}_{0}}\right) \cos \frac{\mathrm{m} \pi \mathrm{x}_{1}}{\mathrm{a}_{0}} \cos \frac{\mathrm{n} \pi \mathrm{y}_{1}}{\mathrm{~b}_{0}} \\
& \mathrm{u}_{1}=\sum_{\mathrm{n}=1}^{\infty} \sum_{\mathrm{m}=1}^{\infty} \mathrm{b}_{\mathrm{mn}} \sin \frac{\mathrm{m} \pi \mathrm{x}_{1}}{\mathrm{a}_{0}} \sin \frac{\mathrm{n} \pi \mathrm{y}_{1}}{\mathrm{~b}_{0}} \\
& \mathrm{v}_{1}=\sum_{\mathrm{n}=1 \mathrm{~m}=1}^{\infty} \sum_{\mathrm{mn}}^{\infty} \mathrm{c}_{\mathrm{m}} \sin \frac{\mathrm{m} \pi \mathrm{x}_{1}}{\mathrm{a}_{0}} \sin \frac{\mathrm{n} \pi \mathrm{y}_{1}}{\mathrm{~b}_{0}} \\
& \mathrm{w}_{2}=\sum_{\mathrm{n}=0}^{\infty} \sum_{\mathrm{m}=0}^{\infty} \mathrm{d}_{\mathrm{mn}}\left(1-\cos \frac{2 \pi \mathrm{x}_{2}}{\mathrm{a}_{0}}\right)\left(1-\cos \frac{2 \pi \mathrm{y}_{2}}{\mathrm{~b}_{0}}\right) \cos \frac{\mathrm{m} \pi \mathrm{x}_{2}}{\mathrm{a}_{0}} \cos \frac{\mathrm{n} \pi \mathrm{y}_{2}}{\mathrm{~b}_{0}} \\
& \mathrm{u}_{2}=\sum_{\mathrm{n}=1 \mathrm{~m}=1}^{\infty} \sum_{\mathrm{m}=1}^{\infty} \mathrm{e}_{\mathrm{mn}} \sin \frac{\mathrm{m} \pi \mathrm{x}_{2}}{\mathrm{a}_{0}} \sin \frac{\mathrm{n} \pi \mathrm{y}_{2}}{\mathrm{~b}_{0}} \\
& \mathrm{v}_{2}=\sum_{\mathrm{n}=1 \mathrm{~m}=1}^{\infty} \sum_{\mathrm{mn}}^{\infty} \mathrm{f}_{\mathrm{m}} \sin \frac{\mathrm{m} \pi \mathrm{x}_{2}}{\mathrm{a}_{0}} \sin \frac{\mathrm{n} \pi \mathrm{y}_{2}}{\mathrm{~b}_{0}}
\end{aligned}
$$

where the outer and inner shell surface areas are projected on a rectangular plane $\mathrm{a}_{0} \mathrm{xb}_{0}$, which is area associated with the mid-surface of the core. The Fourier series selected above satisfy the deflection and slope boundary conditions for a fully clamped sandwich panel. Unlike the case of pinned boundary conditions which is more commonly found in the literature, radial deformations in Eqs. (30) and (33) are non-orthogonal functions and this will be later found to lead to mode coupling in the equations of motion. The sandwich shell was considered to be fully clamped because it is not practical to pin a soft core whether in real life experiments or in FEA. Applying roller supports to simulate pinned boundary conditions may be possible for flat sandwich plates but membrane forces in a curved sandwich plate causes the facesheets to slide instead of rotate at the rollers.

The dynamic response of the sandwich shell is found by satisfying Lagrange's equations of motion: 
$\frac{\mathrm{d}}{\mathrm{dt}}\left(\frac{\partial \mathrm{T}}{\partial \dot{\mathrm{q}}_{\mathrm{mn}}}\right)-\frac{\partial \mathrm{T}}{\partial \mathrm{q}_{\mathrm{mn}}}+\frac{\partial \mathrm{U}}{\partial \mathrm{q}_{\mathrm{mn}}}=\mathrm{Q}_{\mathrm{mn}}$

where $T$ and $U$ are the total kinetic and strain energy in the sandwich shell and $\mathrm{q}_{\mathrm{mn}}$ are generalized coordinates, $\mathrm{a}_{\mathrm{mn}}, \mathrm{b}_{\mathrm{mn}}, \mathrm{c}_{\mathrm{mn}}, \mathrm{d}_{\mathrm{mn}}, \mathrm{e}_{\mathrm{mn}}$ and $\mathrm{f}_{\mathrm{mn}}$, and $\mathrm{Q}_{\mathrm{mn}}$ are generalized forces. Plastic work dissipated during core crushing is accounted for in the strain energy expression.

The kinetic energy of the two facesheets is

$$
\mathrm{T}_{\mathrm{f}}=\frac{1}{2} \rho_{\mathrm{f}} \mathrm{h} \iint_{\mathrm{S}_{1}}\left(\dot{\mathrm{u}}_{1}^{2}+\dot{\mathrm{v}}_{1}^{2}+\dot{\mathrm{w}}_{1}^{2}\right) \mathrm{dx_{1 }} \mathrm{dy}_{1}+\frac{1}{2} \rho_{\mathrm{f}} \mathrm{h} \iint_{\mathrm{S}_{2}}\left(\dot{\mathrm{u}}_{2}^{2}+\dot{\mathrm{v}}_{2}^{2}+\dot{\mathrm{w}}_{2}^{2}\right) \mathrm{dx}_{2} \mathrm{dy}_{2}
$$

where $S_{1}$ and $S_{2}$ are outer and inner facesheet mid-surface areas. The kinetic energy of the core is

$$
\mathrm{T}_{\mathrm{c}}=\frac{1}{2} \rho_{\mathrm{c}} \mathrm{H} \iint_{\mathrm{S}_{0}}\left(\dot{\mathrm{u}}_{0}^{2}+\dot{\mathrm{v}}_{0}^{2}+\dot{\mathrm{w}}_{0}^{2}\right) \mathrm{dxdy}+\frac{1}{24} \rho_{\mathrm{c}} \mathrm{H}^{3} \iint_{\mathrm{S}_{0}}\left(\dot{\phi}_{\mathrm{y}}^{2}+\dot{\phi}_{\mathrm{x}}^{2}\right) \mathrm{dxdy}
$$

where $S_{0}$ is the core mid-surface area. Since $\mathrm{w}_{1}$ and $\mathrm{w}_{2}$ are non-orthogonal functions, the kinetic energy expressions involve coupling of Fourier modes after integration.

Generalized forces $\mathrm{Q}_{\mathrm{mn}}$ are obtained from virtual work $\delta \mathrm{W}$ :

$\mathrm{Q}_{\mathrm{mn}}=\frac{\partial(\delta \mathrm{W})}{\partial\left(\delta \mathrm{q}_{\mathrm{mn}}\right)}$

For uniformly distributed external pressure pulse,

$$
\delta \mathrm{W}=\iint_{\mathrm{S}_{1}} \mathrm{p}(\mathrm{t}) \delta \mathrm{w}_{1} \mathrm{dx}_{1} \mathrm{dy}_{1}=\sum_{\mathrm{n}=0}^{\infty} \sum_{\mathrm{m}=0}^{\infty} \mathrm{Q}_{\mathrm{mn}} \delta \mathrm{a}_{\mathrm{mn}}
$$

Hence,

$$
\mathrm{Q}_{\mathrm{mn}}=\mathrm{p}(\mathrm{t}) \int_{0}^{\mathrm{a}_{0}} \int_{0}^{\mathrm{b}_{0}}\left(1-\cos \frac{2 \pi \mathrm{x}_{1}}{\mathrm{a}_{0}}\right)\left(1-\cos \frac{2 \pi \mathrm{y}_{1}}{\mathrm{~b}_{0}}\right) \cos \frac{\mathrm{m} \pi \mathrm{x}_{1}}{\mathrm{a}_{0}} \cos \frac{\mathrm{n} \pi \mathrm{y}_{1}}{\mathrm{~b}_{0}} \mathrm{dx}_{1} \mathrm{dy}_{1}
$$

The facesheets remain linear elastic even though the core may undergo inelastic deformation during crushing. The elastic facesheet strain energy is

$$
\begin{aligned}
& \mathrm{U}_{\mathrm{f}}=\frac{1}{2} \iint\left(\mathrm{A}_{11} \varepsilon_{\mathrm{s}_{1}, \mathrm{~m}}^{2}+\mathrm{A}_{22} \varepsilon_{\mathrm{y}_{1}, \mathrm{~m}}^{2}+2 \mathrm{~A}_{12} \varepsilon_{\mathrm{x}_{1}, \mathrm{~m}} \varepsilon_{\mathrm{y}_{1}, \mathrm{~m}}+\mathrm{A}_{66} \gamma_{\mathrm{x}_{1} \mathrm{y}_{1}, \mathrm{~m}}^{2}+\mathrm{D}_{11} \kappa_{\mathrm{x}_{1}}^{2}+\mathrm{D}_{22} \kappa_{\mathrm{y}_{1}}^{2}+2 \mathrm{D}_{12} \kappa_{\mathrm{x}_{1}} \kappa_{\mathrm{y}_{1}}+\mathrm{D}_{66} \kappa_{\mathrm{x}_{1} \mathrm{y}_{1}}^{2}\right) d \mathrm{x}_{1} \mathrm{~d} \mathrm{y}_{1} \\
& +\frac{1}{2} \iint\left(\mathrm{A}_{11} \varepsilon_{\mathrm{s}_{2}, \mathrm{~m}}^{2}+\mathrm{A}_{22} \varepsilon_{\mathrm{y}_{2}, \mathrm{~m}}^{2}+2 \mathrm{~A}_{12} \varepsilon_{\mathrm{x}_{2}, \mathrm{~m}} \varepsilon_{\mathrm{y}_{2}, \mathrm{~m}}+\mathrm{A}_{66} \gamma_{\mathrm{x}_{2} \mathrm{y}_{2}, \mathrm{~m}}^{2}+\mathrm{D}_{11} \kappa_{\mathrm{x}_{2}}^{2}+\mathrm{D}_{22} \kappa_{\mathrm{y}_{2}}^{2}+2 \mathrm{D}_{12} \kappa_{\mathrm{x}_{2}} \kappa_{\mathrm{y}_{2}}+\mathrm{D}_{66} \kappa_{\mathrm{x}_{2} \mathrm{y}_{2}}^{2}\right) d \mathrm{x}_{2} \mathrm{dy} \mathrm{d}_{2}
\end{aligned}
$$


Again it should be emphasized that use of non-orthogonal functions for facesheet radial deformations to satisfy the clamped boundary conditions leads to mode coupling after integration in the strain energy. Special cases of purely elastic and elastic-plastic response of the core are considered in the following sections.

\subsubsection{Core elastic response}

During fully elastic response, the stress-strain relation for an orthotropic core is

$$
\left\{\begin{array}{c}
\sigma_{\mathrm{x}} \\
\sigma_{\mathrm{y}} \\
\sigma_{\mathrm{z}} \\
\tau_{\mathrm{yz}} \\
\tau_{\mathrm{zx}} \\
\tau_{\mathrm{xy}}
\end{array}\right\}=\left[\begin{array}{cccccc}
\mathrm{C}_{11} & \mathrm{C}_{12} & \mathrm{C}_{13} & 0 & 0 & 0 \\
\mathrm{C}_{12} & \mathrm{C}_{22} & \mathrm{C}_{23} & 0 & 0 & 0 \\
\mathrm{C}_{13} & \mathrm{C}_{23} & \mathrm{C}_{33} & 0 & 0 & 0 \\
0 & 0 & 0 & \mathrm{C}_{44} & 0 & 0 \\
0 & 0 & 0 & 0 & \mathrm{C}_{55} & 0 \\
0 & 0 & 0 & 0 & 0 & \mathrm{C}_{66}
\end{array}\right]\left\{\begin{array}{l}
\varepsilon_{\mathrm{x}} \\
\varepsilon_{\mathrm{y}} \\
\varepsilon_{\mathrm{z}} \\
\gamma_{\mathrm{yz}} \\
\gamma_{\mathrm{zx}} \\
\gamma_{\mathrm{xy}}
\end{array}\right\}
$$

where $C_{i j}$ are the elastic stiffness components. The elastic strain energy is therefore given by

$$
\mathrm{U}_{\mathrm{c}}=\frac{1}{2} \iiint_{\mathrm{V}_{0}}\left(\mathrm{C}_{11} \varepsilon_{\mathrm{x}}^{2}+\mathrm{C}_{22} \varepsilon_{\mathrm{y}}^{2}+\mathrm{C}_{33} \varepsilon_{\mathrm{z}}^{2}+2 \mathrm{C}_{12} \varepsilon_{\mathrm{x}} \varepsilon_{\mathrm{y}}+2 \mathrm{C}_{23} \varepsilon_{\mathrm{y}} \varepsilon_{\mathrm{z}}+2 \mathrm{C}_{13} \varepsilon_{\mathrm{z}} \varepsilon_{\mathrm{x}}+\mathrm{C}_{44} \gamma_{\mathrm{yz}}^{2}+\mathrm{C}_{55} \gamma_{\mathrm{zx}}^{2}+\mathrm{C}_{66} \gamma_{\mathrm{xy}}^{2}\right) \mathrm{dzdxdy}
$$

where $\mathrm{V}_{0}$ is the volume of the core enclosed between the two facesheets. If the foam is transversely isotropic with respect to the 1-2 plane, $\mathrm{C}_{22}=\mathrm{C}_{11} \mathrm{C}_{13}=\mathrm{C}_{23}, \mathrm{C}_{55}=\mathrm{C}_{44}$, and $C_{66}=\left(C_{11}-C_{12}\right) / 2$. If the foam is assumed to be isotropic, then $\mathrm{C}_{33}=\mathrm{C}_{22}=\mathrm{C}_{11}, \quad \mathrm{C}_{23}=\mathrm{C}_{13}=\mathrm{C}_{12} \quad$ and $\mathrm{C}_{66}=\mathrm{C}_{55}=\mathrm{C}_{44}=\left(\mathrm{C}_{11}-\mathrm{C}_{12}\right) / 2$.

\subsubsection{Core elastic-plastic response}

Cellular foam exhibits elastic-plastic behavior under both compression and shear [18, 19, 28]. Yield criteria for an isotropic foam and transversely isotropic foam are described in this section. After initial yield, it is assumed that continued plastic flow or deformations can be represented by a nonlinear elastic stress-strain response. Deformation theories of plasticity have been used extensively in practice because of their simplicity and are accurate as long as unloading does not occur. In addition to this, non-hardening or perfectly plastic behavior is assumed to take place after initial yield. A representative stress-strain behavior for one component of the generalized three-dimensional stressstrain state of the foam is shown in Fig. 2 where $\varepsilon_{\mathrm{ij} 0}$ and $\sigma_{\mathrm{ij} 0}$ are the strain and stress components at 
the initial yield. The physical soundness of plasticity deformation theory for loading paths other than proportional loading has been studied on the basis of Drucker's postulate by Budiansky [29]. These assumptions are made in order to avoid mathematical complexities associated with satisfying a threedimensional plasticity flow rule and at the same time allow plastic response to be incorporated into Lagrange's equation of motion.

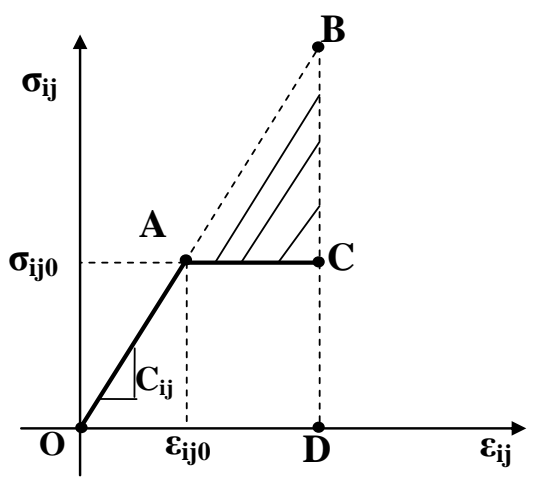

Figure 2 Elastic-plastic stress-strain response; strain energy in plastic region is area under OACD.

Isotropic yielding. One of the most commonly used criteria to describe plastic yielding is an isotropic foam yielding [28] of the form

$$
\mathrm{F}=\frac{\hat{\sigma}}{\sigma_{0}}=1
$$

where $\sigma_{0}$ is the flow stress and the effective stress $\hat{\sigma}$ is given in terms of the mean stress $\sigma_{\mathrm{m}}$ and von Mises equivalent stress $\sigma_{\mathrm{e}}$ :

$$
\hat{\sigma}^{2}=\frac{1}{\left[1+\left(\frac{\alpha}{3}\right)^{2}\right]}\left(\sigma_{\mathrm{e}}^{2}+\alpha_{\mathrm{p}}^{2} \sigma_{\mathrm{m}}^{2}\right)
$$

and $\alpha=3 / \sqrt{2}$ if the foam plastic Poisson's ratio is assumed to be zero.

Transversely isotropic yielding. Gdoutos et al. [19] have shown that under biaxial loading, failure of PVC H250 foam is best described by a Tsai-Wu failure criterion. Foam failure in Ref. [19] is defined as fracture when the foam is subjected to tension and/or shear, while foam failure is considered to be initial yielding when the core is in pure compression and/or shear. Although this study was restricted 
to biaxial loading (or plane stress), it is assumed that the Tsai-Wu failure criterion could be applied to a general three-dimensional stress state for the PVC H250 foam. The initial yield criterion for the transversely isotropic foam is as follows:

$\mathrm{F}=2 \mathrm{X}_{1} \sigma_{1}+\mathrm{X}_{3} \sigma_{3}+2 \mathrm{X}_{11} \sigma_{1}^{2}+\mathrm{X}_{33} \sigma_{3}^{2}+2 \mathrm{X}_{55} \sigma_{13}^{2}+\mathrm{X}_{66} \sigma_{12}^{2}+2 \mathrm{X}_{12} \sigma_{1}^{2}+4 \mathrm{X}_{13} \sigma_{1} \sigma_{3}=1$

where $X_{1}=\frac{1}{X_{t}}-\frac{1}{X_{c}}, X_{3}=\frac{1}{Z_{t}}-\frac{1}{Z_{c}}, X_{11}=\frac{1}{X_{t} X_{c}}, X_{33}=\frac{1}{Z_{t} Z_{c}}, X_{55}=\left(\frac{1}{S_{13}}\right)^{2}$,

$\mathrm{X}_{66}=\left(\frac{1}{\mathrm{~S}_{12}}\right)^{2}, \mathrm{X}_{12}=\frac{-\mathrm{X}_{11}}{2}, \mathrm{X}_{13}=\frac{-1}{2} \sqrt{\mathrm{X}_{11} \mathrm{X}_{33}}$, and $\mathrm{X}_{\mathrm{t}}, \mathrm{X}_{\mathrm{c}}, \mathrm{Z}_{\mathrm{t}}$ and $\mathrm{Z}_{\mathrm{c}}$ are the in-plane and out-ofplane tensile and compressive strengths (subscripts " $\mathrm{t}$ " and "c" denote tension and compression).

Plastic response after initial yield. The strain energy in the plastic core regions are approximated by nonlinear elastic strain energy density enclosed in Region OACD of Fig. 2. The area under OACD is equivalent to the area under OBD minus the area of shaded triangle $\mathrm{ABC}$. Hence the core strain energy can be expressed by

$$
\begin{aligned}
& \mathrm{U}_{\mathrm{c}}=\frac{1}{2} \iiint_{\mathrm{V}_{\mathrm{e}}}\left(\mathrm{C}_{11} \varepsilon_{\mathrm{x}}^{2}+\mathrm{C}_{22} \varepsilon_{\mathrm{y}}^{2}+\mathrm{C}_{33} \varepsilon_{\mathrm{z}}^{2}+2 \mathrm{C}_{12} \varepsilon_{\mathrm{x}} \varepsilon_{\mathrm{y}}+2 \mathrm{C}_{23} \varepsilon_{\mathrm{y}} \varepsilon_{\mathrm{z}}+2 \mathrm{C}_{13} \varepsilon_{\mathrm{z}} \varepsilon_{\mathrm{x}}+\mathrm{C}_{44} \gamma_{\mathrm{yz}}^{2}+\mathrm{C}_{55} \gamma_{\mathrm{zx}}^{2}+\mathrm{C}_{66} \gamma_{\mathrm{xy}}^{2}\right) \mathrm{dzdxdy} \\
& +\frac{1}{2} \iiint_{\mathrm{V}_{\mathrm{p}}}\left(\mathrm{C}_{11} \varepsilon_{\mathrm{x}}^{2}+\mathrm{C}_{22} \varepsilon_{\mathrm{y}}^{2}+\mathrm{C}_{33} \varepsilon_{\mathrm{z}}^{2}+2 \mathrm{C}_{12} \varepsilon_{\mathrm{x}} \varepsilon_{\mathrm{y}}+2 \mathrm{C}_{23} \varepsilon_{\mathrm{y}} \varepsilon_{\mathrm{z}}+2 \mathrm{C}_{13} \varepsilon_{\mathrm{z}} \varepsilon_{\mathrm{x}}+\mathrm{C}_{44} \gamma_{\mathrm{yz}}^{2}+\mathrm{C}_{55} \gamma_{\mathrm{zx}}^{2}+\mathrm{C}_{66} \gamma_{\mathrm{xy}}^{2}\right) \mathrm{dzdxdy} \\
& -\frac{1}{2} \iiint_{\mathrm{V}_{\mathrm{p}}}\left[\mathrm{C}_{11}\left(\varepsilon_{\mathrm{x}}-\varepsilon_{\mathrm{x} 0}\right)^{2}+\mathrm{C}_{22}\left(\varepsilon_{\mathrm{y}}-\varepsilon_{\mathrm{y} 0}\right)^{2}+\mathrm{C}_{33}\left(\varepsilon_{\mathrm{z}}-\varepsilon_{\mathrm{z} 0}\right)^{2}+2 \mathrm{C}_{12}\left(\varepsilon_{\mathrm{x}}-\varepsilon_{\mathrm{x} 0}\right)\left(\varepsilon_{\mathrm{y}}-\varepsilon_{\mathrm{y} 0}\right)+2 \mathrm{C}_{23}\left(\varepsilon_{\mathrm{y}}-\varepsilon_{\mathrm{y} 0}\right)\left(\varepsilon_{\mathrm{z}}-\varepsilon_{\mathrm{z} 0}\right)\right. \\
& \left.+2 \mathrm{C}_{13}\left(\varepsilon_{\mathrm{z}}-\varepsilon_{\mathrm{z} 0}\right)\left(\varepsilon_{\mathrm{x}}-\varepsilon_{\mathrm{x} 0}\right)+\mathrm{C}_{44}\left(\gamma_{\mathrm{yz}}-\gamma_{\mathrm{yz} 0}\right)^{2}+\mathrm{C}_{55}\left(\gamma_{\mathrm{zx}}-\gamma_{\mathrm{zx} 0}\right)^{2}+\mathrm{C}_{66}\left(\gamma_{\mathrm{xy}}-\gamma_{\mathrm{xy} 0}\right)^{2}\right] \mathrm{dzdxdy}
\end{aligned}
$$

where $\mathrm{V}_{\mathrm{e}}$ and $\mathrm{V}_{\mathrm{p}}$ are the volumes of foam core undergoing purely elastic and elastic-plastic behavior. The above expression is simplified as follows:

$$
\begin{aligned}
& \mathrm{U}_{\mathrm{c}}=\frac{1}{2} \iiint_{\mathrm{V}_{\mathrm{e}}}\left(\mathrm{C}_{11} \varepsilon_{\mathrm{x}}^{2}+\mathrm{C}_{22} \varepsilon_{\mathrm{y}}^{2}+\mathrm{C}_{33} \varepsilon_{\mathrm{z}}^{2}+2 \mathrm{C}_{12} \varepsilon_{\mathrm{x}} \varepsilon_{\mathrm{y}}+2 \mathrm{C}_{23} \varepsilon_{\mathrm{y}} \varepsilon_{\mathrm{z}}+2 \mathrm{C}_{13} \varepsilon_{\mathrm{z}} \varepsilon_{\mathrm{x}}+\mathrm{C}_{44} \gamma_{\mathrm{yz}}^{2}+\mathrm{C}_{55} \gamma_{\mathrm{zx}}^{2}+\mathrm{C}_{66} \gamma_{\mathrm{xy}}^{2}\right) \mathrm{dzdxdy} \\
& +\iiint_{V_{p}}\left[C_{11} \varepsilon_{x} \varepsilon_{x} 0+C_{22} \varepsilon_{y} \varepsilon_{y 0}+C_{33} \varepsilon_{z} \varepsilon_{z 0}+C_{12}\left(\varepsilon_{x} \varepsilon_{y 0}+\varepsilon_{y} \varepsilon_{x 0}\right)+C_{23}\left(\varepsilon_{y} \varepsilon_{z 0}+\varepsilon_{z} \varepsilon_{y 0}\right)+C_{13}\left(\varepsilon_{z} \varepsilon_{x}+\varepsilon_{x} \varepsilon_{z 0}\right)\right. \\
& \left.+\mathrm{C}_{44} \gamma_{\mathrm{yz}} \gamma_{\mathrm{yz} 0}+\mathrm{C}_{55} \gamma_{\mathrm{zx}} \gamma_{\mathrm{zx} 0}+\mathrm{C}_{66} \gamma_{\mathrm{xy}} \gamma_{\mathrm{xy} 0}\right] \mathrm{dzdx} d \mathrm{dy} \\
& -\frac{1}{2} \iiint_{\mathrm{V}_{\mathrm{p}}}\left(\mathrm{C}_{11} \varepsilon_{\mathrm{x} 0}^{2}+\mathrm{C}_{22} \varepsilon_{\mathrm{y} 0}^{2}+\mathrm{C}_{33} \varepsilon_{z 0}^{2}+2 \mathrm{C}_{12} \varepsilon_{\mathrm{x} 0} \varepsilon_{\mathrm{y} 0}+2 \mathrm{C}_{23} \varepsilon_{\mathrm{y} 0} \varepsilon_{\mathrm{z} 0}+2 \mathrm{C}_{13} \varepsilon_{\mathrm{z} 0} \varepsilon_{\mathrm{x} 0}+\mathrm{C}_{44} \gamma_{\mathrm{y} \mathrm{y} 0}^{2}+\mathrm{C}_{55} \gamma_{\mathrm{zx} 0}^{2}+\mathrm{C}_{66} \gamma_{\mathrm{xy} 0}^{2}\right) \mathrm{dz} \mathrm{dx} \mathrm{dy}
\end{aligned}
$$


When Eq. (49) is expanded in Fourier terms and integrated over the shell surface area, reduced stiffness and negative damping forces are introduced into Lagrange's equations of motion as a consequence of the first and last integral terms. The last integral does not depend on generalized coordinates or Fourier coefficients and is only a function of the size of the plastic zone since it is integrated over $\mathrm{V}_{\mathrm{p}}$.

\section{Predicted Response with Isotropic and Transversely Core}

As an example, consider a composite sandwich shell with $\mathrm{h}=5.08 \mathrm{~mm}, \mathrm{H}=25.4 \mathrm{~mm}$, $\mathrm{R}_{\mathrm{x}_{1}}=\mathrm{R}_{\mathrm{y}_{1}}=726.44 \mathrm{~mm}, \mathrm{R}_{\mathrm{x}_{2}}=\mathrm{R}_{\mathrm{y}_{2}}=695.96 \mathrm{~mm}$, and $\mathrm{a}_{0}=\mathrm{b}_{0}=248.25 \mathrm{~mm}$. The facesheet is $\mathrm{E}-$ Glass/Vinyl Ester Woven Roving and the core is Divinycell PVC H250. Table 1 shows properties of the E-Glass Vinyl Ester. Elastic and plastic properties of the Divinycell PVC H250 are taken from data provided in Gdoutos et al. [19] and these are summarized in Tables 2 and 3 assuming the foam is isotropic and transversely isotropic. In Table $3, \mathrm{X}_{\mathrm{c}}, \mathrm{Y}_{\mathrm{c}}$ and $\mathrm{Z}_{\mathrm{c}}$ are the in-plane and out-of-plane compressive yield strengths, while $S_{12}$ and $S_{13} / S_{23}$ are the in-plane and out-of-plane shear yield strengths. The compressive stress-strain response in the through-thickness or transverse directions is used when assuming the foam is isotropic. This panel is subjected to uniformly distributed pressure pulse loading with load duration $1 \mathrm{~ms}$ and peak pressure 2.3 MPa.

Table 1 Material properties of 0/90 Woven Roving E-glass/Vinyl Ester.

\begin{tabular}{|c|c|c|c|c|c|c|c|c|c|}
\hline $\begin{array}{c}\mathrm{E}_{11}=\mathrm{E}_{22} \\
(\mathrm{GPa})\end{array}$ & $\begin{array}{c}\mathrm{E}_{33} \\
(\mathrm{GPa})\end{array}$ & $v_{12}$ & $v_{13}=v_{23}$ & $\begin{array}{c}\mathrm{G}_{12} \\
(\mathrm{MPa})\end{array}$ & $\begin{array}{c}\mathrm{G}_{13}=\mathrm{G}_{23} \\
(\mathrm{MPa})\end{array}$ & $\begin{array}{c}\mathrm{X}_{\mathrm{c}} / \mathrm{X}_{\mathrm{t}}= \\
\mathrm{Y}_{\mathrm{c}} / \mathrm{Y}_{\mathrm{t}} \\
(\mathrm{MPa})\end{array}$ & $\begin{array}{c}\mathrm{Z}_{\mathrm{c}} / \mathrm{Z}_{\mathrm{t}} \\
(\mathrm{MPa})\end{array}$ & $\begin{array}{c}\mathrm{S}_{13}=\mathrm{S}_{23} \\
(\mathrm{MPa})\end{array}$ & $\begin{array}{c}\mathrm{S}_{12} \\
(\mathrm{MPa})\end{array}$ \\
\hline 17 & 7.48 & 0.13 & 0.28 & 4 & 1.73 & $200 / 270$ & $343 / 23.2$ & 31.6 & 40 \\
\hline
\end{tabular}

Table 2 Assumed isotropic properties of PVC H250.

\begin{tabular}{|c|c|c|c|}
\hline E (MPa) & $v$ & $\begin{array}{c}\mathrm{G} \\
(\mathrm{MPa})\end{array}$ & $\begin{array}{c}\sigma_{0} \\
(\mathrm{MPa})\end{array}$ \\
\hline 403 & 0.34 & 117 & 6.3 \\
\hline
\end{tabular}


Table 3 Transversely isotropic properties of PVC H250 [19].

\begin{tabular}{|c|c|c|c|c|c|c|c|c|c|}
\hline $\begin{array}{c}\mathrm{E}_{11}=\mathrm{E}_{22} \\
(\mathrm{MPa})\end{array}$ & $\begin{array}{c}\mathrm{E}_{33} \\
(\mathrm{MPa})\end{array}$ & $v_{12}$ & $v_{13}=v_{23}$ & $\begin{array}{c}\mathrm{G}_{12} \\
(\mathrm{MPa})\end{array}$ & $\begin{array}{c}\mathrm{G}_{13}=\mathrm{G}_{23} \\
(\mathrm{MPa})\end{array}$ & $\begin{array}{c}\mathrm{X}_{\mathrm{c}} / \mathrm{X}_{\mathrm{t}}= \\
\mathrm{Y}_{\mathrm{c}} / \mathrm{Y}_{\mathrm{t}} \\
(\mathrm{MPa})\end{array}$ & $\begin{array}{c}\mathrm{Z}_{\mathrm{c}} / \mathrm{Z}_{\mathrm{t}} \\
(\mathrm{MPa})\end{array}$ & $\begin{array}{c}\mathrm{S}_{13}=\mathrm{S}_{23} \\
(\mathrm{MPa})\end{array}$ & $\begin{array}{c}\mathrm{S}_{12} \\
(\mathrm{MPa})\end{array}$ \\
\hline 236 & 403 & 0.2 & 0.34 & 85 & 117 & $4.5 / 7.3$ & $6.3 / 10$ & 5 & 3.9 \\
\hline
\end{tabular}

\subsection{Isotropic foam core}

Equations of motion were solved for the Fourier coefficients described in Eqs. (30)-(35) using MATLAB ode45 solver with relative and absolute tolerances set at $1 \mathrm{e}^{-4}$ and $1 \mathrm{e}^{-6}$, respectively. The MATLAB ode45 is a variable time step solver, based on an explicit Runge-Kutta $(4,5)$ formula, the Dormand-Prince pair. The Fourier series was expanded to $n=m=6$ or a total of 242 Fourier terms in $a_{m n}, b_{m n}, c_{m n}, d_{m n}, e_{m n}$ and $f_{m n}$ because it was deemed that having these number of terms would provide the required accuracy for predicting both deformation and stresses in the sandwich shell. It is shown in Appendix A that the assumed double Fourier series converge rapidly for transverse deflection ( $\mathrm{n}=\mathrm{m}=2$ or 34 terms), but it would take $\mathrm{n}=\mathrm{m}=6$ or 242 terms to adequately obtain stresses in the facesheet and subsequently in the core. On a Dell Quad Core 2.4 GHz and 24GB RAM workstation, the program took about 18 hours to complete on a single processor.

The elastic-plastic response of the composite sandwich shell is obtained in two parts: (1) complete linear elastic response up to the point of initial yielding in the core and (2) elastic-plastic response as the plastic zone spreads in the core. The yield criterion, Eq. (45), must be evaluated during elastic response until it is met. Yielding in the core mid-surface was found to initiate and spread into the four cross-hatched line regions shown in Fig. 3. The elastic-plastic boundary shown in Fig. 3 occurs at $0.25 \mathrm{~ms}$. Prediction of this boundary from FEA (dashed lines), which is discussed in Appendix B, is also shown in Fig. 3 for comparison. The equations of motion during elastic-plastic response incorporated the spread of the plastic zone because it is introduced in the integration limits of the core strain energy in Eq. (49). 


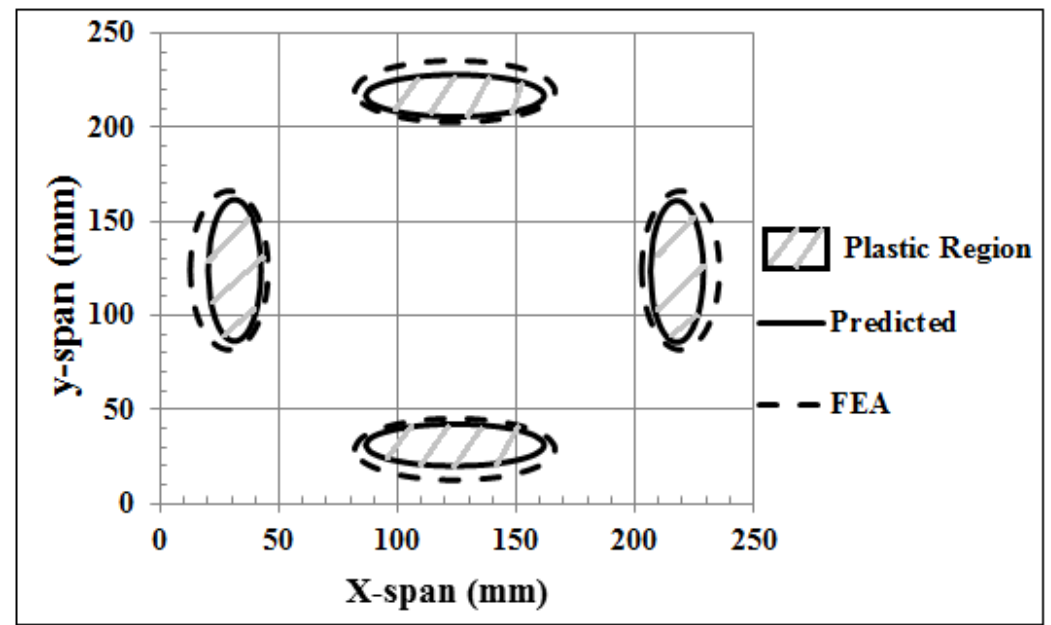

Figure 3 Elastic and plastic regions in core mid-surface at $\mathrm{t}=0.25 \mathrm{~ms}$.

The transient deflections of the mid-surface of the core along $y=b_{0} / 2$ are shown in Fig. 4. The panel reaches maximum deflection at a value of $3 \mathrm{~mm}$ at $0.25 \mathrm{~ms}$ before rebounding. Solutions from finite element analysis in Appendix B, are also shown in these figures for comparison. The distribution of stresses at the mid-surface of the core along $y=b_{0} / 2$ were calculated from Eq. (43), and are shown at $\mathrm{t}=0.16 \mathrm{~ms}$ in Figs. 5 (a) and (b) for the in-plane and out-of-plane stress components, respectively. While the core mid-surface deflections are in very good agreement with FEA, stresses at the core mid-surface and in the facesheets are not captured as well, especially at the clamped boundaries. This is a consequence of the first-order approximations that were made for transverse shear and compressive strains in order to simplify the core kinematics. 


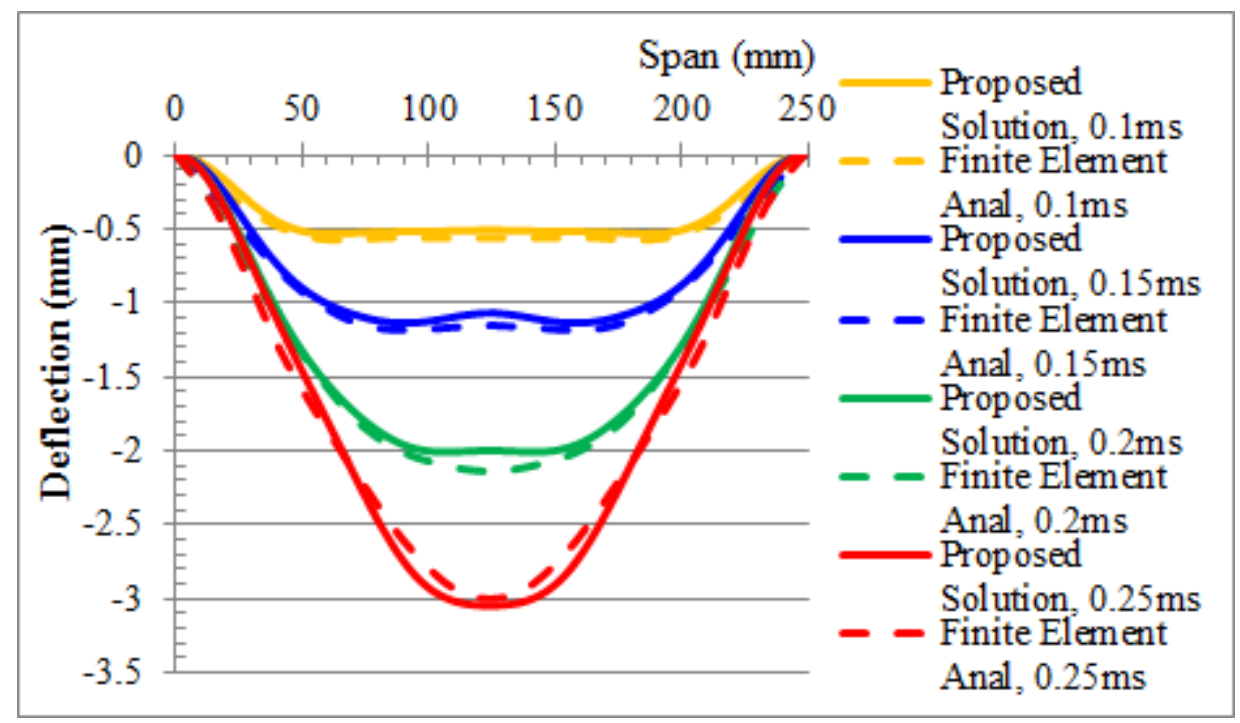

Figure 4 Transient deflections at mid-surface of core along $\mathrm{y}=\mathrm{b}_{0} / 2$, assuming isotropic core.

The magnitudes of the in-plane compressive stresses are greater than that of the out-of-plane compressive stress. This indicates that transversely isotropic foam properties would be needed to accurately determine the foam stress. The maximum out-of-plane or transverse shear stress is about twice the magnitude of the highest normal compressive stress suggesting that foam failure would be predominantly due to transverse shear. Before the foam fails, however, it would yield. Yielding is determined by the foam initial yield criterion. The equivalent stress as defined in Eq. (46) is also shown at various times in Fig. 6. There is relatively good agreement between predicted effective stresses and FEA. Yielding occurs when this equivalent stress is equal to the yield strength for the PVC $\mathrm{H} 250$ foam, which is $6.3 \mathrm{MPa}$. It was calculated that at $\mathrm{t}=0.18 \mathrm{~ms}$, plasticity would just initiate at $x=27.13 \mathrm{~mm}, 221.12 \mathrm{~mm}$, and this is approximately the same as was found in the FEA. Plastic zones in the foam core will occur when the equivalent stress exceeds this value. The plastic zones are distributed as shown in Fig. 3 throughout the entire mid-surface. A similar plastic region also occurs in core mid-surface from the FEA. 


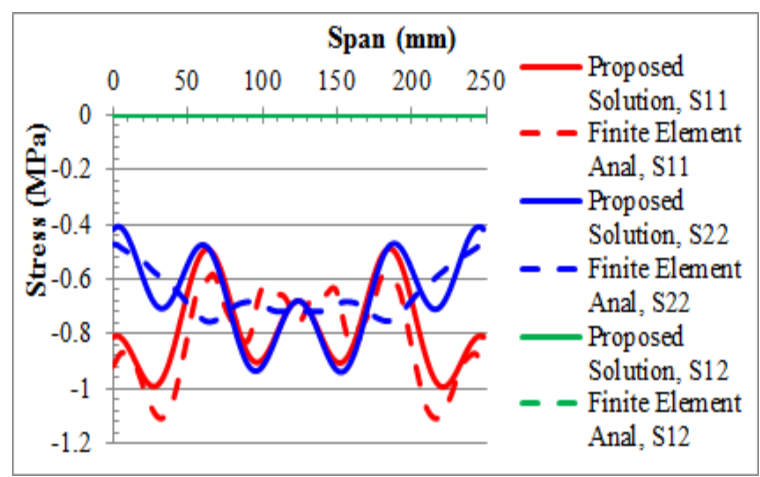

(a)

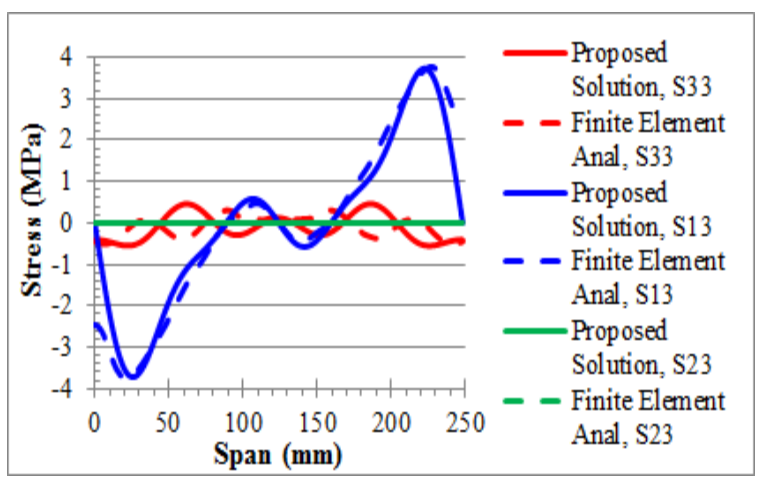

(b)

Figure 5 Stress distribution in isotropic core mid-surface along $\mathrm{y}=\mathrm{b}_{0} / 2$ at $\mathrm{t}=0.16 \mathrm{~ms}$ : (a) in-plane stress components and (b) out-of-plane stress components.

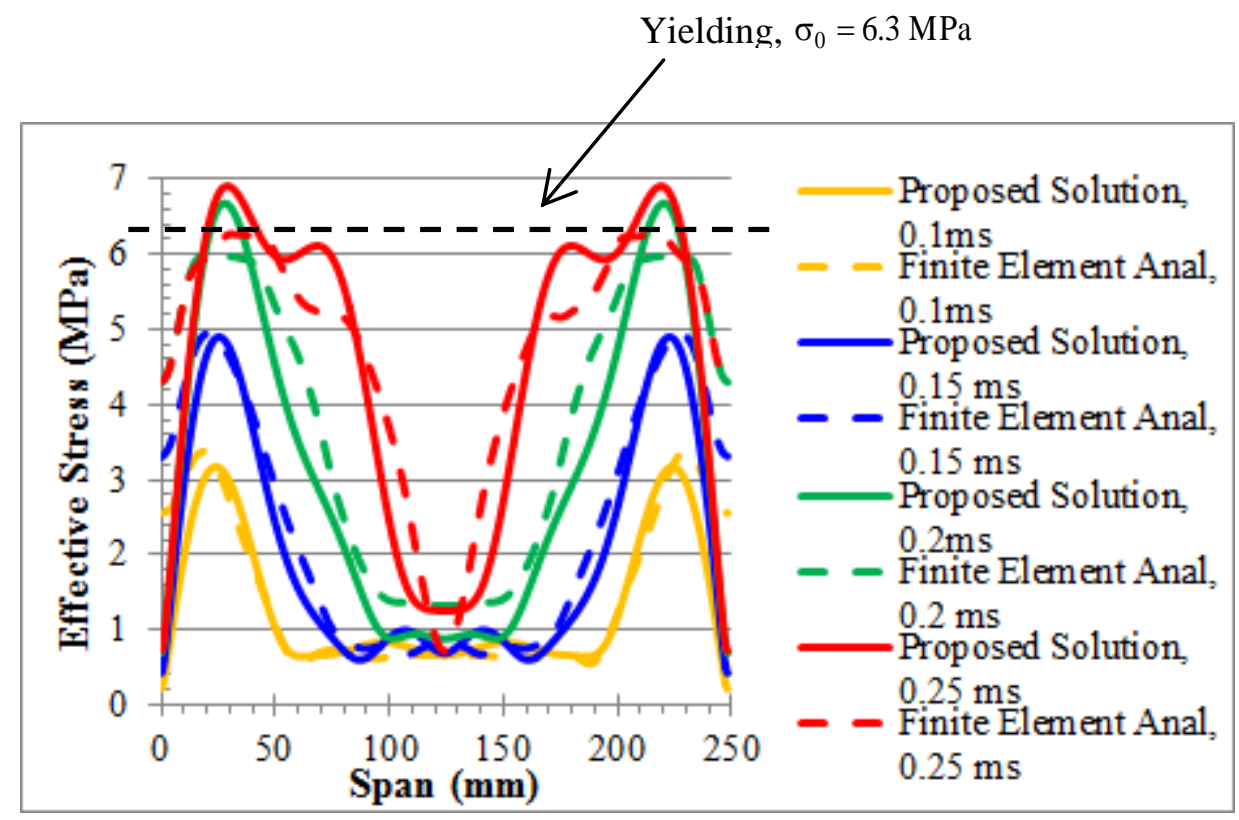

Figure 6 Equivalent stress distribution in isotropic core mid-surface along $\mathrm{y}=\mathrm{b}_{0} / 2$, at various times.

Facesheet stresses in the composite sandwich shell at the maximum deflection are shown in Figs. 7(a) - (d). The stresses are shown at the top and bottom side of each facesheet where failure would most likely occur. Again the corresponding FEA stresses are shown for comparison, and there is relatively good agreement between the analytical model prediction and FEA. The highest in-plane 
compressive stress occurs at the edge of the panel on the bottom side of the inner facesheet. Compression failure of the facesheet would be most likely to occur here. Simple failure criteria that can be used to predict the blast resistance of the sandwich shell are introduced in a later section.

\subsection{Transversely isotropic foam core}

To observe the effect of transversely isotropic properties in the foam, transversely isotropic properties of the foam from Table 3 were assumed instead. The load was kept the same as in the isotropic case, i.e., a peak pressure of $2.3 \mathrm{MPa}$ and load duration of $1 \mathrm{~ms}$. Again the elastic-plastic response of the composite sandwich shell was obtained for complete linear elastic response up to the point of initial yielding in the core and elastic-plastic response as the plastic zone spreads in the core. The Tsai-Wu yield criterion, Eq. (47), was used to determine core plasticity. Yielding in the core mid-surface was also found to initiate and spread into the four regions similar to those shown in Fig.

3.

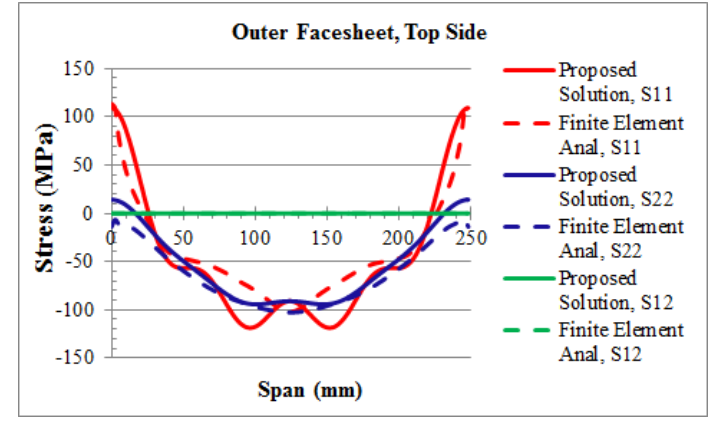

(a)

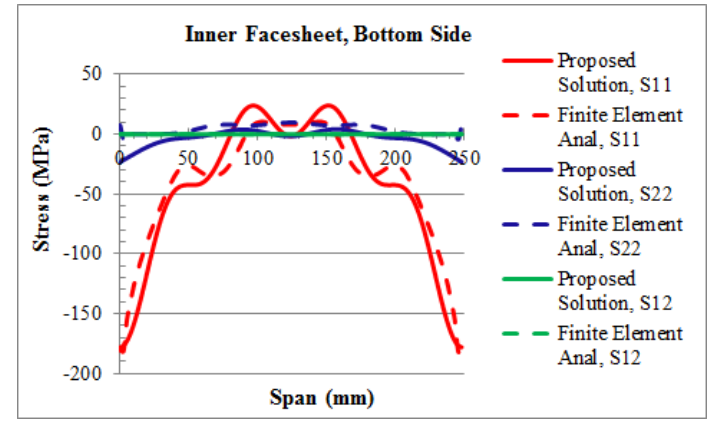

(c)

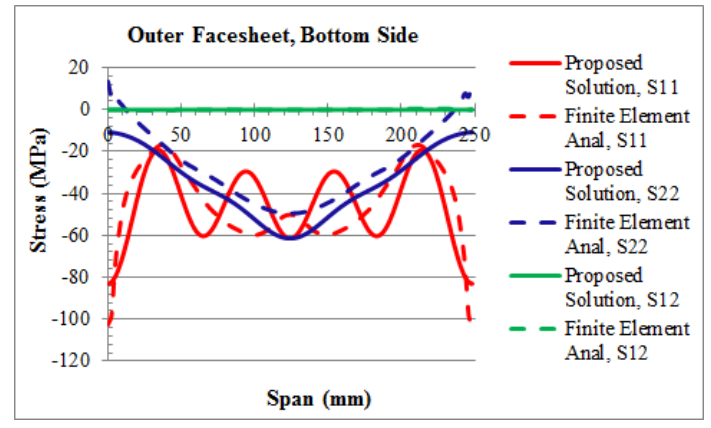

(b)

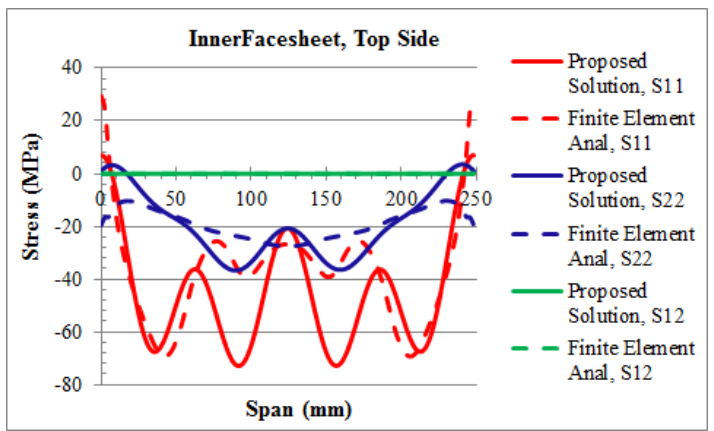

(d)

Figure 7 Stress distribution in facesheets of sandwich shell with isotropic core along $\mathrm{y}_{1}=\mathrm{b}_{0} / 2$ or $\mathrm{y}_{2}=\mathrm{b}_{0} / 2$ and at $\mathrm{t}=0.25 \mathrm{~ms}$ (maximum defection): (a) outer facesheet, top side, (b) outer facesheet, bottom side, (c) inner facesheet, top side, and (d) inner facesheet, bottom side. 
A comparison of the panel center deflection assuming isotropic and transversely isotropic elastic-plastic core is shown in Fig. 8. The panel reaches a maximum deflection of $2.6 \mathrm{~mm}$ at $0.23 \mathrm{~ms}$ assuming transversely isotropic core, while it was at a maximum deflection of $3 \mathrm{~mm}$ at $0.25 \mathrm{~ms}$ assuming isotropic core. The maximum deflection is considered to be just before the rebounding in both cases. A reason why the sandwich shell with transversely isotropic core rebounds earlier with a smaller deflection than the shell with the isotropic core has to do with changes in core plasticity when the Tsai-Wu yield criterion is used instead of the isotropic crushable foam criterion. The failure index used to determine initial yield and the extent of the plastic zone is given in Figs. 9 (a) and (b) for the shell with isotropic core and transversely isotropic core, respectively. Plasticity initiated in the isotropic core at $0.18 \mathrm{~ms}$, while it initiated later at $0.22 \mathrm{~ms}$ in the transversely isotropic core. There is actually very little plasticity in the transversely isotropic core before the panel rebounds. In fact, only the last $0.01 \mathrm{~ms}$ is spent in elastic-plastic core deformations.

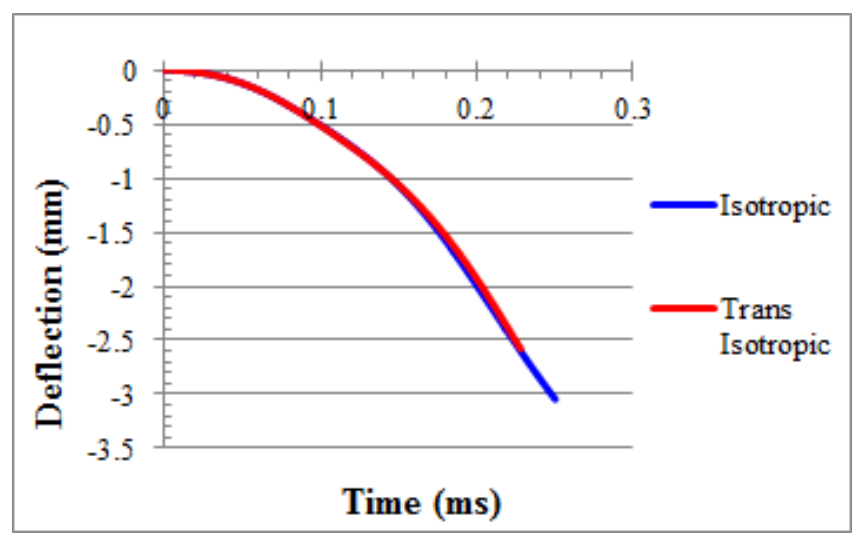

Figure 8 Comparison of panel center deflections at core mid-surface assuming isotropic and transversely isotropic core. 


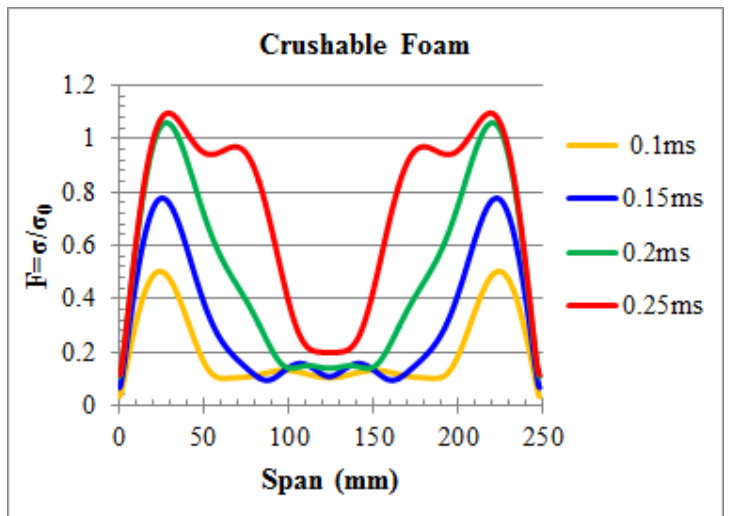

(a)

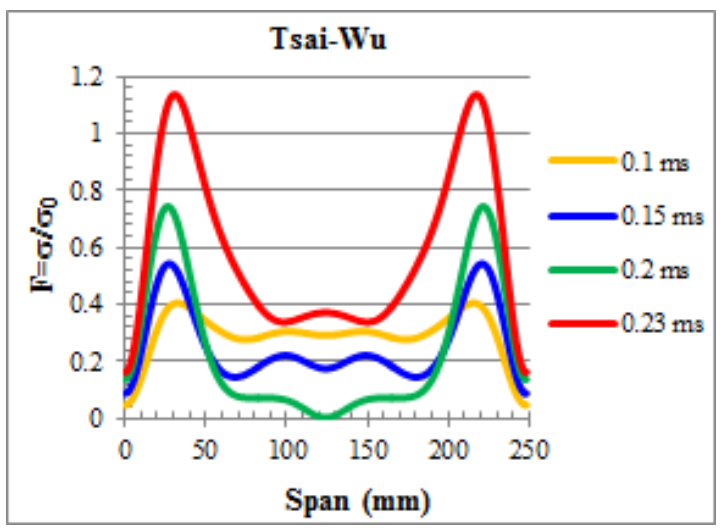

(b)

Figure 9 Distribution of failure index in core mid-surface along $\mathrm{y}=\mathrm{b}_{0} / 2(\mathrm{~F}=1$ denotes yielding and plastic zone): (a) isotropic crushable foam and (b) transversely isotropic Tsai-Wu foam.

Even though the sandwich shell with the transversely isotropic foam core has a lower maximum deflection, the inner facesheet stresses at peak deflections are slightly higher than the shell with an isotropic foam core. As in the case of an isotropic core, the highest in-plane compressive stress occurs at the edge of the panel on the bottom side of the inner facesheet. The maximum inplane compressive stress at the panel edges of the bottom side of the inner facesheet is $187 \mathrm{MPa}$, while it is $178 \mathrm{MPa}$ in the sandwich shell with the isotropic core. The panel failure pressure or blast resistance would be therefore over-predicted using an assumption of isotropic crushable foam model if the core was indeed transversely isotropic.

\section{Failure of Sandwich Shell}

If the pressure pulse amplitude is high enough, the sandwich shell may fail by foam or facesheet fracture, and these are illustrated in Fig. 10. Only damage initiation in either the facesheet or core is considered in this paper. Simple failure criteria are established for each mode below. 


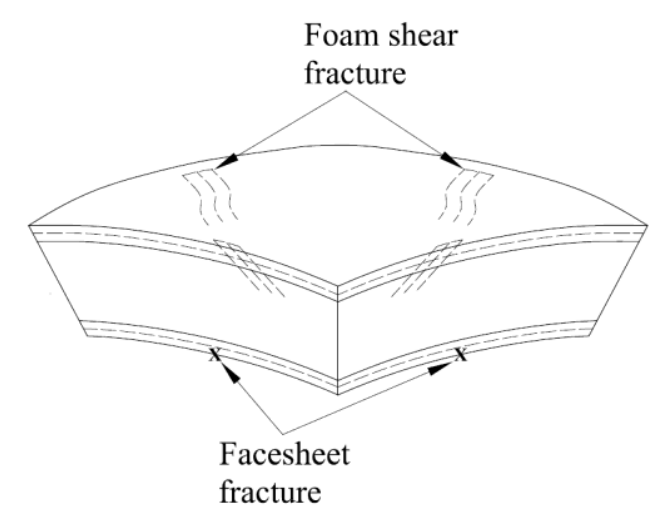

Figure 10 Failure modes in sandwich shell.

\subsection{Facesheet failure}

A modified Hashin-Rotem criterion is used to examine lamina failure of the woven roving EGlass/Vinyl Ester [30]. The reader is referred to Ref. [2] for more refined damage analysis of the facesheets during blast loading. For the orthotropic shell, the relationship between the principal stresses and strains are given by

$$
\left\{\begin{array}{c}
\sigma_{\mathrm{x}} \\
\sigma_{\mathrm{y}} \\
\tau_{\mathrm{xy}}
\end{array}\right\}=\left[\begin{array}{ccc}
\overline{\mathrm{Q}}_{11} & \overline{\mathrm{Q}}_{12} & 0 \\
\overline{\mathrm{Q}}_{12} & \overline{\mathrm{Q}}_{22} & 0 \\
0 & 0 & \overline{\mathrm{Q}}_{66}
\end{array}\right]\left\{\begin{array}{l}
\varepsilon_{\mathrm{x}} \\
\varepsilon_{\mathrm{y}} \\
\gamma_{\mathrm{xy}}
\end{array}\right\}
$$

where $\bar{Q}_{11}=E_{11} /\left(1-v_{12} v_{21}\right), \bar{Q}_{22}=E_{22} /\left(1-v_{12} v_{21}\right), \bar{Q}_{12}=v_{12} E_{22} /\left(1-v_{12} v_{21}\right)$, and $\bar{Q}_{66}=G_{12}$.

According to the modified Hashin-Rotem failure criteria, the failure of the composite occurs when

$$
\begin{aligned}
& \frac{\left|\sigma_{\mathrm{x}}\right|}{\mathrm{X}_{\mathrm{t}}}=1 \text { if } \sigma_{x}>0 \text { or } \frac{\left|\sigma_{\mathrm{x}}\right|}{\mathrm{X}_{\mathrm{c}}}=1 \text { if } \sigma_{\mathrm{x}}<0 \\
& \frac{\left|\sigma_{\mathrm{y}}\right|}{\mathrm{Y}_{\mathrm{t}}}=1 \text { if } \sigma_{\mathrm{y}}>0 \text { or } \frac{\left|\sigma_{\mathrm{y}}\right|}{\mathrm{Y}_{\mathrm{c}}}=1 \text { if } \sigma_{\mathrm{y}}<0
\end{aligned}
$$

and

$$
\frac{\left|\tau_{\mathrm{xy}}\right|}{S_{12}}=1
$$


where $X_{t}$ and $X_{c}$ are the tensile and compressive strength in the $\mathrm{X}$-direction; $Y_{t}$ and $Y_{c}$ are the tensile and compressive strength in y-direction; and $S_{12}$ is the in-plane shear strength. Strengths for the E-Glass Vinyl Ester are given in Table 1. For the E-Glass Vinyl Ester, in-plane compressive stresses were found to be highest at the clamped edges on the on the bottom side of the inner facesheet (see Figs. 7(a)-(d)). Thus compressive failure is predicted by either Eqs. (51) or (52).

\subsection{Core failure}

The stress distributions in the core shown Figs. 5 (a) and (b) indicate that transverse shear stresses dominate all other stress components, when and where yielding begins. The points of yielding are also where the foam would tear if the strains exceed the foam ductility. Tearing occurs after yielding $[18,19]$. Although core fracture is of a mixed-mode involving not just transverse shear, but also in-plane stress and out-of-plane compression, it is driven mostly by transverse shear deformations. A simple criterion for the onset of core shear failure is to set the transverse shear strain in the core equal to the core transverse fracture strain, $\gamma_{\mathrm{f}}$. which for PVC H250 is 0.45 . In other words, core shear failure occurs when

$\gamma_{\mathrm{xz}}=\phi_{\mathrm{y}}+\frac{\partial \mathrm{w}_{0}}{\partial \mathrm{x}}-\frac{\mathrm{u}_{0}}{\mathrm{R}_{\mathrm{x}}}=\gamma_{\mathrm{f}}$

and

$\gamma_{\mathrm{yz}}=\phi_{\mathrm{x}}+\frac{\partial \mathrm{w}_{0}}{\partial \mathrm{y}}-\frac{\mathrm{v}_{0}}{\mathrm{R}_{\mathrm{y}}}=\gamma_{\mathrm{f}}$

The transverse shear strains in the core were found to be highest approximately $25 \mathrm{~mm}$ from the panel edges, as indicated by the plastic zones of Fig. 3. Core shear failure occurs when this value reaches the core transverse fracture strain.

\section{Influence of Transverse Isotropy}

The effect of the transversely isotropic core properties would become more apparent when the sandwich shell radius of curvature decreases. A smaller radius of curvature or higher curvature leads to more in-plane membrane compression for the transversely externally loaded shell. A shell with a 
very large radius of curvature approaches a flat panel in which in-plane membrane stresses would be insignificant compared to out-of-plane bending and shear stresses. A parametric study was done in order to see how the blast resistance of a composite sandwich shell would vary assuming that the core was isotropic and transversely isotropic. Failure could be either due to core shear or facesheet fracture, as defined in the previous section.

The parametric study was done on a sandwich shell with E-Glass/Vinyl Ester Woven Roving facesheets and a Divinycell PVC H250 foam core. In order to isolate the effect of curvature, the facesheet and core thickness were kept at $\mathrm{h}=5.08 \mathrm{~mm}$ and $\mathrm{H}=25.4 \mathrm{~mm}$, and the span was also kept constant $\mathrm{a}_{0}=\mathrm{b}_{0}=248.25 \mathrm{~mm}$. This meant that the aspect ratio of the sandwich shell, $\mathrm{a}_{0} / \mathrm{h}_{\text {tot }}$ where $h_{\text {tot }}=2 h+H$, would be fixed. The radius of curvature of the facesheets could then be varied accordingly, while still maintaining shallow shell assumptions. A curvature ratio was defined as $\mathrm{R}_{0} / \mathrm{h}_{\text {tot }}$, and it was allowed to vary from 10 to 50 . This range of curvature ratio translated to shell angular extent that ranged from 7 to $20 \mathrm{deg}$, thereby ensuring that the shallow shell assumptions were valid.

Figure 11 summarizes the results of this parametric study involving blast resistance and curvature ratio for shells with isotropic and transversely isotropic cores. In all cases, compressive failure of the back side of the inner facesheet was found to be the mode of failure. The PVC H250 core did not exhibit transverse shear failure. The failure pressure generally decreases as the curvature ratio increases or as the panel becomes flatter. This is to be expected because shells are designed to carry greater transverse loads through the membrane compression. When $R_{0} / h_{\text {tot }} \geq 30$, there is very little difference in the failure pressure when the core is assumed to isotropic and transversely isotropic. Essentially both sandwich shells are acting like a flat sandwich panel and there is little membrane stress transmitted in the core. However, as $\mathrm{R}_{0} / \mathrm{h}_{\text {tot }}$ becomes smaller than 20 , the blast resistance of the sandwich shell with the isotropic core is seen to be higher than that calculated for the sandwich shell with a transversely isotropic core. One may observe from Table 3 that in-plane stiffness and yield strengths of the transversely isotropic foam are lower than in the isotropic foam, 
and as a result the sandwich panel fails at a lower load under the assumption of transversely isotropic core.

Although the difference is small, about $6 \%$, the results indicate the importance of using the correct in-plane foam properties when addressing blast resistance of applying composite sandwich shells. The sandwich shells considered in this parametric study were geometrically restricted to shallow shell assumptions, but even greater deviation in the blast resistance with isotropic and transversely isotropic core would be expected of a deep sandwich shell which has greater in-plane membrane contributions. From a practical engineering standpoint, this implies that the isotropic core assumption which is widely-used in the literature has the potential to give non-conservative estimates of blast resistance in composite sandwich shells.

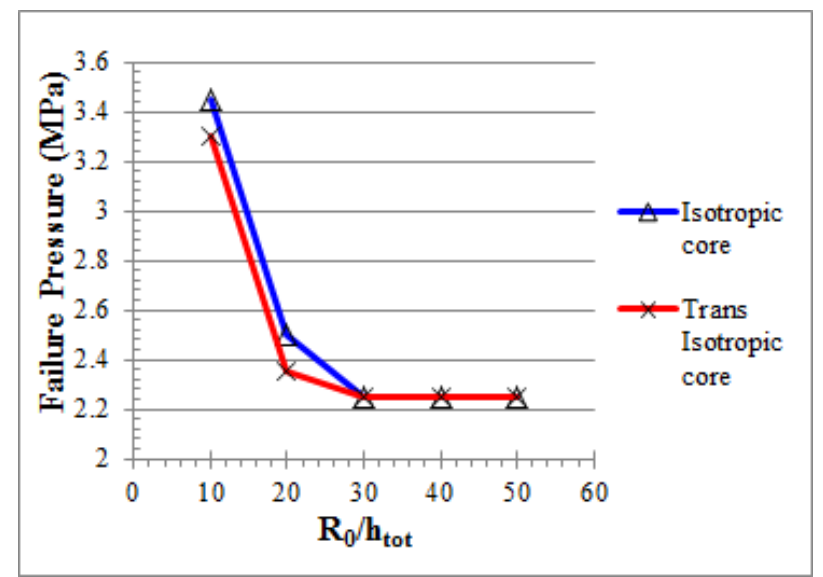

Figure 11 Variation of failure pressure (blast resistance) with sandwich shell curvature ratio (shell becomes flat panel as radius-to-thickness ratio increases).

\section{Concluding Remarks}

An analytical model for the blast response of a fully clamped, double-curvature, composite sandwich shallow shell with a crushable foam core was developed. In developing this model, the sandwich facesheets and core were assumed to perfectly bonded to each other, and changes in material properties due strain rates were neglected. Lagrange's equations of motion were used to describe the sandwich shell response with an isotropic and a transversely isotropic elastic-plastic core. The predicted transient response, including deformations and stresses in facesheets and core, was found to be in good agreement with Finite Elements (ABAQUS Explicit) results assuming an isotropic crushable core. 
The elastic-plastic analysis was used to determine the blast resistance of a sandwich shell with E-Glass/Vinyl Ester Woven Roving facesheets and a Divinycell PVC H250 foam core. Panel failure due to transverse shear cracking of the core and facesheet failure were considered. All the sandwich shells considered in the study were found to fail by compressive failure of the inner facesheet. A parametric study indicated that the blast resistance of the sandwich shells increases as the curvature ratio decreases because shells are designed to carry greater transverse loads through the action of membrane compression. The parametric study also showed that the blast resistance of the sandwich shell with the isotropic core became higher than that calculated for the sandwich shell a transversely isotropic core as the shell radius of curvature decreased. This not only indicated the importance of using the correct in-plane foam properties for some shell configurations but it also implied that modeling the core of the sandwich shell as isotropic would give non-conservative estimates of the structure's ability to resist blast loading.

\section{Acknowledgement}

The authors would like to acknowledge financial support from Dr. Yapa Rajapakse at the Office of Naval Research under Grant N00014-11-1-0485. 


\section{Appendix A: Convergence of Deflection and Stresses with Double Fourier Series}

Equations of motion were solved using MATLAB ode45 solver with relative and absolute tolerances set at $1 \mathrm{e}^{-4}$ and $1 \mathrm{e}^{-6}$, respectively, and assuming a finite number of coefficients or degrees of freedom described in double Fourier series of Eqs. (30)-(35). The transverse shell deflection taken at the center of the core mid-surface plane $\left(\mathrm{x}=\mathrm{a}_{0} / 2, \mathrm{y}=\mathrm{b}_{0} / 2\right)$ was first taken as a quantity of interest. Figure A1(a) shows the transient deflection when the Fourier series are expanded up to $\mathrm{n}=\mathrm{m}=2,4,6$ and even 8 , while Fig. A1(b) shows the corresponding deflection profile at the midsurface of core along $\mathrm{y}=\mathrm{b}_{0} / 2$ when $\mathrm{t}=0.25 \mathrm{~ms}$. The Fourier series converge very rapidly for deflection, and very good approximations of the transient deflection could be achieved when $\mathrm{n}=\mathrm{m}=2$ or 32 Fourier terms in $\mathrm{a}_{\mathrm{mn}}, \mathrm{b}_{\mathrm{mn}}, \mathrm{c}_{\mathrm{mn}}, \mathrm{d}_{\mathrm{mn}}, \mathrm{e}_{\mathrm{mn}}$ and $\mathrm{f}_{\mathrm{mn}}$ are taken.

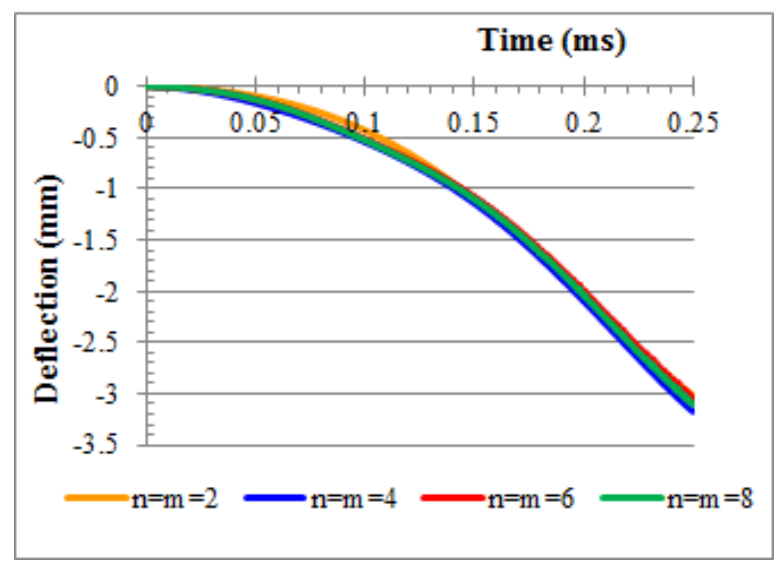

(a)

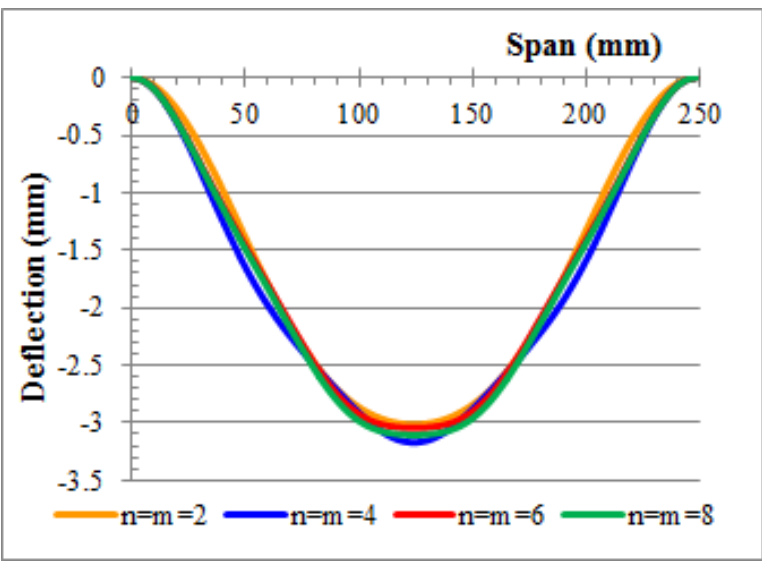

(b)

Figure A1 Convergence of Fourier series for transverse deflection: (a) transient deflection at center of core mid-surface plane and (b) transverse deflections at mid-surface of core along $y=b_{0} / 2$ when $\mathrm{t}=0.25 \mathrm{~ms}$.

The in-plane stress $\sigma_{1}$ at the bottom side of the inner facesheet (see Fig. 7(d)) was taken as the second quantity of interest since it would contribute to the facesheet failure predictions. This stress is highest at the clamped edges, and the stress history at clamped edge at the bottom side of the inner facesheet $\left(\mathrm{x}_{2}=\mathrm{a}_{0}, \mathrm{y}_{2}=\mathrm{b}_{0} / 2\right)$ is shown when the Fourier series were expanded up to $\mathrm{n}=\mathrm{m}=2,4,6$ and 8 in Fig. A2(a). The stress distribution along $\mathrm{y}_{2}=\mathrm{b}_{0} / 2$ when $\mathrm{t}=0.25 \mathrm{~ms}$ is also 
shown in Fig. A2(b) for the corresponding Fourier expansions. Unlike deflections, stresses do not converge as rapidly but it can be seen that a good approximation for stress is obtained when $\mathrm{n}=\mathrm{m}=6$. In other words, the series converge for stresses when $\mathrm{n}=\mathrm{m}=6$ or 242 Fourier terms in $a_{m n}, b_{m n}, c_{m n}, d_{m n}, e_{m n}$ and $f_{m n}$.

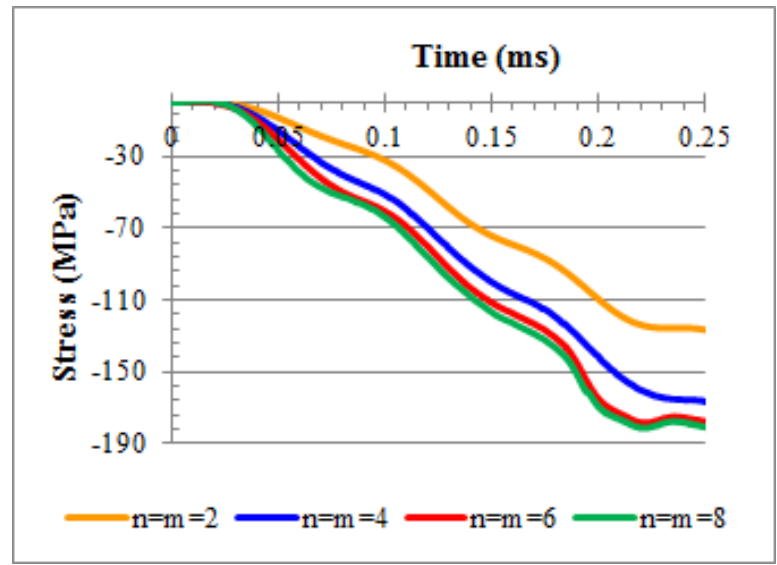

(a)

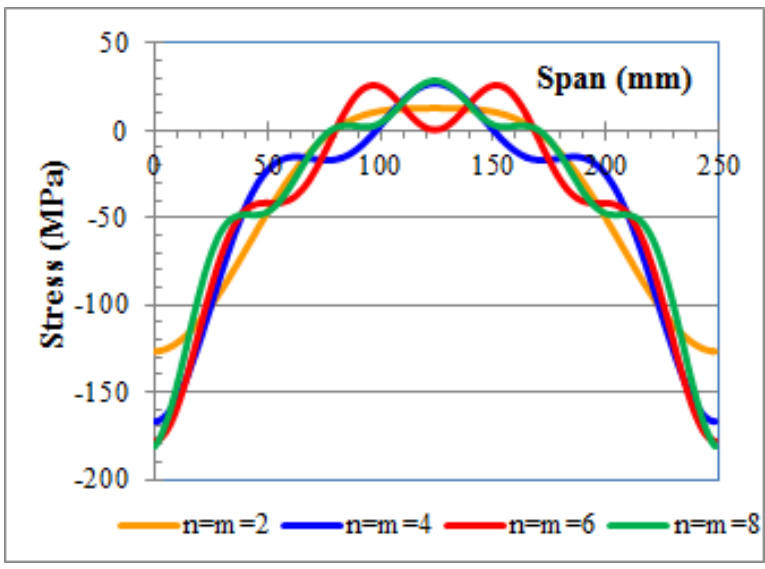

(b)

Figure A2 Convergence of Fourier series for in-plane stress $\left(\sigma_{1}\right.$ or $\left.S_{11}\right)$ at the bottom side of the inner facesheet: (a) stress history at clamped edge $\mathrm{x}_{2}=\mathrm{a}_{0}, \mathrm{y}_{2}=\mathrm{b}_{0} / 2$ and (b) stress distribution along $\mathrm{y}_{2}=\mathrm{b}_{0} / 2$ when $\mathrm{t}=0.25 \mathrm{~ms}$.

\section{Appendix B: Finite Element Analysis for Shell with Isotropic Foam Crushing}

Finite element analysis using ABAQUS Explicit was used to corroborate results from the analytical model. Dynamic, Explicit analysis was used to obtain the transient response of the sandwich panel. The FEA model for the sandwich shell is shown in Fig. B1. The dimensions of the sandwich shell are the same as in the example problem described in Section 3. The facesheets were rigidly tied to the core. All sides of the sandwich shell were encastre. The facesheets were orthotropic, linear elastic with properties of E-Glass/Vinyl Ester Woven Roving (Table 1). The core was modeled with PVC H250 properties assuming crushable foam with isotropic hardening (Table 2). A uniformly distributed pressure, expressed by Eq. (1) where $\mathrm{p}_{0}=2.3 \mathrm{MPa}$ and $\Delta \mathrm{T}=1 \mathrm{~ms}$, was applied to the outer facesheet of the sandwich shell. 


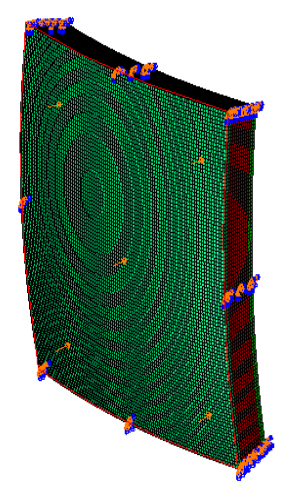

Figure B1 FEA model of the sandwich shell.

Continuum eight node (C3D8) or brick elements were chosen for both facesheets and core. The mesh density was chosen to give accurate results with respect to quantities of interest such as the transient deflection at center of core mid-surface plane and the stress $S_{11}$ history at clamped edge $\mathrm{x}_{2}=\mathrm{a}_{0}, \mathrm{y}_{2}=\mathrm{b}_{0} / 2$ of the bottom side of the inner facesheet. Figures B2 (a) and (b) show results for above-mentioned deflection and stress history with 4,375 to 140,000 elements. The mesh convergence study indicated that a total of 140,000 elements were needed to assure accurate FEA results. Solutions for the mid-surface core deflections and stresses along $y=b_{0} / 2$ at various times from the FEA are given in Figs. 4- 6. The FEA stresses along $y=b_{0} / 2$ axis at the top and bottom sides of each facesheet are shown alongside analytical predictions in Figs. 7(a)-(d) at $t=0.25 \mathrm{~ms}$, when deflections are at a maximum. 


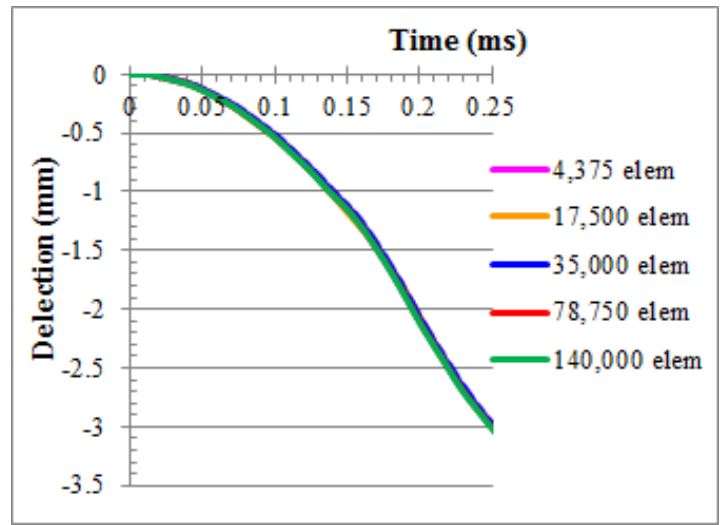

(a)

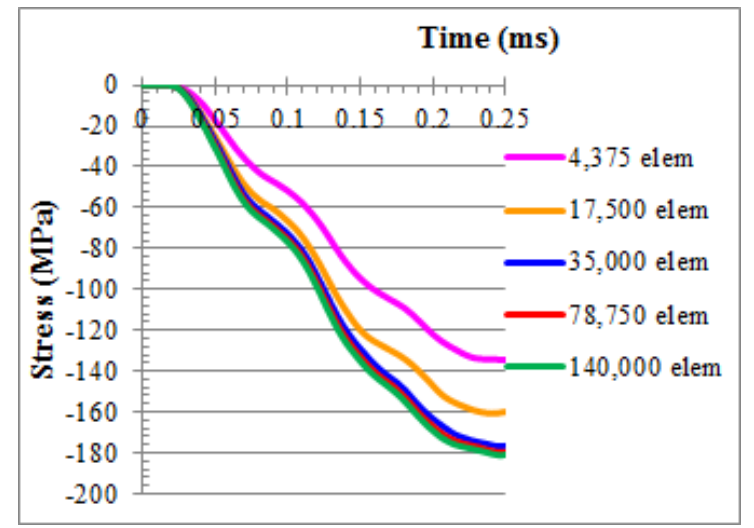

(b)

Figure B2 Mesh convergence for (a) transient deflection at center of core mid-surface plane and (b) $\mathrm{S}_{11}$ history at clamped edge $\mathrm{x}_{2}=\mathrm{a}_{0}, \mathrm{y}_{2}=\mathrm{b}_{0} / 2$ of the bottom side of the inner facesheet.

\section{References}

[1] Porfiri M and Gupta N. A review of research on impulsive loading of marine composites. In: E.E. Gdoutos, I.M. Daniel, Y.D.S. Rajapakse, editors, Major accomplishments in composite materials and sandwich structures - an anthology of ONR sponsored research, Springer, 2010, p. 169-194.

[2] Batra RC and Hassan NM. Blast resistance of unidirectional fiber reinforced composites. Composites Part B: Engineering 2008; 39(3):513-536.

[3] Hohe $\mathbf{J}$ and Librescu L. A nonlinear theory for doubly curved anisotropic sandwich shells with transversely compressible core. Int J Solids Struct 2003; 40: 1059-1099.

[4] Hause T and Librescu L. Dynamic response of doubly-curved anisotropic sandwich panels impacted by blast loadings. Int J Solids Struct 2007; 44: 6678-6700.

[5] Hohe J and Librescu L. Recent results on the effect of the transverse core compressibility on the static and dynamic response of sandwich structures. Comp Part B: Eng 2009; 38: 108-119.

[6] Li R, Kardomateas GA and Simitses GJ. Nonlinear response of a shallow sandwich shell with compressible core to blast loading. ASME J Appl Mech 2008; 75.

[7] Tekalur SA, Bogdanovich AE and Shukla A. Shock loading response of sandwich panels with 3D woven E-glass composite skins and stitched foam core. Comp Sci Tech 2009; 69(6): 736-753.

[8] Wang E and Shukla A. Blast performance of sandwich composites with in-plane compressive loading. Exp Mech 2012; 52(1):49-58.

[9] Arora H, Hooper PA and Dear JP. Dynamic response of full-scale sandwich composite structures subject to air-blast loading. Comp Part A: Appl Sci Manuf 2011; 42(11):1651-1662.

[10] Arora H, Hooper PA and Dear JP. The effects of air and underwater blast on composite sandwich panels and tubular laminate structures. Exp Mech 2012; 52(1):59-81.

[11] Wang E, Gardner N and Shukla A. The blast resistance of sandwich composites with stepwise 
graded cores. Int J Sol Struct 2009; 46(18-19): 3492-3502.

[12] Gardner N, Wang E, Kumar, P and Shukla A. Blast mitigation in a sandwich composite using graded core and polyurea interlayer. Exp Mech 2012, 52(2):119-133.

[13] Hoo Fatt MS, Surabhi H and Gao Y. Blast response of sandwich shells with crushable foam cores. Comp Struc 2012; 94: 3174-3185.

[14] Hoo Fatt MS and Chapagain P. Pressure pulse response of composite sandwich panels with plastic core damping. J Sandwich Struct Mat 2012; 14(4): 392-429.

[15] Hoo Fatt MS, Gao Y and Sirivolu D. Foam-core composite sandwich shells under blast. J Sand Struct Mat 2013, 15(3): 261-291.

[16] Gao Y and Hoo Fatt MS. Local facesheet pulse buckling in a curved, composite sandwich panel. Comp Struct 2013; 104: 249-260.

[17] Hoo Fatt MS and Sirivolu D. Foam crushing in double-curvature, composite sandwich panels subjected to blast. In the Proceedings of the $19^{\text {th }}$ International Conference on Composite Materials, Montreal, Canada, July 28-August 2, 2013.

[18] Chen L and Hoo Fatt MS. Transversely isotropic mechanical properties of PVC foam under cyclic loading. J Mat Sci 2013; 48(19):6786-6796.

[19] Gdoutos EE, Daniel IM and Wang KA. Failure of cellular foams under multiaxial loading. Composite: Part A: Appl Sci Manuf 2002; 33:163-176.

[20] Vlasov VZ. General theory of shells and its applications in engineering, NASA Technical Translation TTF-99, Washington DC, 1964.

[21] Lee JK, Leissa AW and Wang AJ. Vibrations of cantilevered circular cylindrical shells: shallow versus deep shell theory. Int J Mech Sci 1983; 25(5): 361-383.

[22] Lim CW, Kitipornchai S and Liew KM. Comparative accuracy of shallow and deep shell theories for vibration of cylindrical shells. J Vibration \& Control 1997, 3: 119-143.

[23] Peter ST. Handbook of Composites, $2^{\text {nd }}$ Ed, Chapman \& Hall, London, 1998.

[24] Gdoutos EE and Daniel IM. Failure modes of composite sandwich beams. Theoret. Appl. Mech. 2008; 35(1-3): 105-117.

[25] Al-Hassani STS and Kaddour AS. Strain rate effects on GRP, KRP and CFRP composite laminates. Key Engineering Materials 1997; 141-143: 427-452.

[26] Mines RAW. Strain rate effects in crushable structural foams. Applied Mechanics and Materials 2007; 7-8: 231-236.

[27] Amabili M. Nonlinear Vibrations and Stability of Shells and Plates, Cambridge Univ Press, Cambridge, 2008.

[28] Deshpande VS and Fleck NA. Multi-axial yield behavior of polymer foams. Acta Mater 2001; 49:1859-1866.

[29] Budiansky B. A reassessment of deformation theories of plasticity. ASME J Appl Mech 1959, 26: 259-264. 
[30] Daniel IM. Failure of composite materials. Strain 2007; 43: 4-12. 